Article

\title{
Trade-Old-for-Remanufactured Closed-Loop Supply Chains with Carbon Tax and Government Subsidies
}

\author{
Tong Shu ${ }^{1}{ }^{1}$, Chunfen Huang ${ }^{1}$, Shou Chen ${ }^{1}$, Shouyang Wang ${ }^{2}$ and Kin Keung Lai ${ }^{3,4, *}$ \\ 1 Business School, Hunan University, Changsha 410082, China; shutong@hnu.edu.cn (T.S.); \\ cfhuang@hnu.edu.cn (C.H.); chenshou@hnu.edu.cn (S.C.) \\ 2 Academy of Mathematics and System Science, Chinese Academy of Sciences, Beijing 100190, China; \\ sywang@amss.ac.cn \\ 3 International Business School, Shaanxi Normal University, Xi'an 710062, China \\ 4 Department of Industrial and Manufacturing Systems Engineering, Hong Kong University, Pokfulam Road, \\ Hong Kong, China \\ * Correspondence: mskklai@outlook.com
}

Received: 7 October 2018; Accepted: 27 October 2018; Published: 29 October 2018

check for updates

\begin{abstract}
The constantly increasing $\mathrm{CO}_{2}$ emissions are threatening the environment tremendously. Facing the pressure of environmental activists and public opinion, businesses and governments are taking action to reduce carbon emissions. Among these endeavors, carbon tax and subsidy policies proposed by governments are widely adopted. Remanufacturing is believed to save manufacturing costs and reduce carbon emissions from the process of enterprise operation, and it is increasingly being accepted by enterprises. However, different consumers' willingness to pay for remanufactured products and the durability of new products will also affect consumers' willingness to buy remanufactured products. Therefore, considering the discrepancy between consumer willingness to pay and product durability, we established the trade-old-for-remanufactured (TOR) model for a scenario of carbon tax and government subsidies. Through the analysis of the model, we obtained the optimal pricing and production decisions of manufacturers (remanufacturers) in the case of carbon tax and government subsidies. Our results show that, when there is no carbon tax constraint, the increase in consumer willingness to pay and the adjustment in product durability can stimulate consumers to participate in TOR projects and augment enterprises' profits. However, it can also lead to a carbon rebound that increases corporate carbon emissions. When there is a carbon tax constraint, the introduction of carbon tax contributes to a reduction in carbon emissions, while enterprises tend to lose profits. In order to achieve a "win-win" between corporate profits and carbon emissions, we considered government subsidy policies. Our numerical examples illustrate that appropriate carbon tax and government subsidies can curb carbon emissions and also increase profits for enterprises.
\end{abstract}

Keywords: trade-old-for-remanufactured; consumer willingness to pay; product durability; carbon tax; government subsidies

\section{Introduction}

Environmental pollution has already threatened human survival and health and is a growing concern for citizens across the entire globe [1]. Scientists predict that, within this century, global warming could give rise to an array of natural disasters, such as flooding, drought, rising sea levels, and melting glaciers (also called the El Nino Phenomenon). The overrun of carbon emissions can be considered the major contributor to global warming. To curb carbon emissions, enterprises and governments seek solutions to decrease operation-related carbon emissions to reduce the carbon footprints of supply chains [2,3]. A case in point is the carbon tax of 10 Canadian dollars on each ton 
of $\mathrm{CO}_{2}$ emitted implemented in British Columbia on 1 July 2008. In July 2014, the carbon tax rose to 25 US dollars on each ton of $\mathrm{CO}_{2}$ [4]. Empirical and simulation models demonstrate that carbon tax results in a decline of $5-15 \%$ in carbon emissions [5]. Additionally, governments encourage emission reduction by means of subsidies. The Chinese government introduced subsidies for trade-old-for-new (TON) programs covering household appliances and automobiles on 1 June 2009. Consumers can obtain $10 \%$ replacement subsidies in relation to the prices of some household appliances, with an aim of encouraging consumers to purchase more energy-efficient household appliances or automobiles. Subsidies under this policy could add up to a total of 43 billion US dollars [6]. To increase the demand for remanufactured products and encourage the recycling of waste products, a number of enterprises and governments have initiated Trade-Old-for-Remanufactured (TOR) programs, a process in which consumers purchase remanufactured products at replacement prices by returning their waste products [7]. TON aims to encourage consumers possessing waste products to purchase new products by offering discounts. Meanwhile, TOR stimulates consumers to return their used products and purchase remanufactured products by offering discounts. For example, the Chinese government announced pilot TOR programs in 2013 to push remanufacturing and improve environmental performance. Subsequently, 10 automobile and engine manufacturers were chosen as pilot enterprises for TOR programs [8]. TON can stimulate the demand for new products, while TOR can accelerate the demand for remanufactured products. In addition, the price of remanufactured products is usually $30 \sim 40 \%$ of the cost of new products [9]. Remanufacturing has been proved to reduce manufacturing costs and reduce carbon emissions. However, carbon tax greatly increases the operating costs of a business and can have a negative impact on its profits [10]. Remanufacturing, carbon taxes, and subsidies affect manufacturers' production and operating costs. Consequently, carbon tax, subsidies, TON, and TOR can extensively affect manufacturers' production decisions, facilitating the reduction of carbon emissions.

Although carbon cap-and-trade is widely adopted, carbon tax is considered the most stable policy to facilitate remanufacturing, and it is the fastest and cheapest means to curb the emissions of global greenhouse gases, with more social welfare and almost no negative impact on economic growth while effectively curbing carbon emissions [11-14]. Hence, we use carbon taxes rather than cap-and-trade as a means of reducing emissions. Additionally, TOR with government subsidies can stimulate consumers to participate in TOR programs, though it may lead to an increase in carbon emissions. The carbon tax increases the manufacturing cost for enterprises, leading to the increase of wholesale and retail prices of products, thus reducing the number of consumers who buy new products and remanufactured products, which can reduce the carbon emissions of enterprises, but, at the same time, it also causes the loss of profits of enterprises. Government subsidies to consumers can increase sales and offset this loss of profits. Therefore, to increase corporate profits and reduce carbon emissions, we must study TOR in the context of carbon taxes and government subsidies. Currently, first and foremost, much research is centered on the issue of TOR pricing and whether TOR and TON should be offered simultaneously, under the assumption that consumers fail to differentiate new products from remanufactured products. Secondly, while the impacts on carbon emissions from enterprises mainly involve manufacturing and transportation processes, our article considers these impacts from a brand new perspective: that is, the impacts of consumers' willingness to pay for remanufactured products and the durability of new products on carbon emissions from enterprises implementing TOR programs. Thirdly, prior literature has only considered the provision of subsidies for consumers involved in TOR programs, while our article argues that governments should offer subsidies to consumers in TOR programs but also levy carbon tax. Without carbon tax, governments should not provide subsidies to consumers participating in TOR programs. For these reasons, our article reflects a situation that is closer to reality. The issue of whether TOR programs with carbon tax and government subsidies can reduce carbon emissions and increase corporate profits has not been investigated. As a result, the contribution of our article resides in presenting the optimal strategy of TOR programs with carbon tax and government subsidies, with the aim of deriving the appropriate range of government subsidies and carbon tax. 
Although TOR programs have been accepted by administrators, as mentioned above, TOR poses an enormous challenge. Consequently, below are the research questions our article aims to answer.

(1) Under what circumstances should enterprises implement TOR programs? What are the optimal pricing and production strategies?

(2) How do carbon tax, government subsidies, consumers' willingness to pay for remanufactured products, and the durability of new products impact corporate profits and carbon emissions of enterprises under TOR programs? How do they affect the environment?

(3) How do government subsidies affect the TOR program with carbon tax? What are the optimal strategies of governments?

To summarize, our paper mainly has three contributions. Firstly, we developed a two-stage model, presented here. Under the assumption that consumers are able to differentiate new products from remanufactured products, the impacts of TOR programs with carbon tax on carbon emissions from enterprises are explored, and a manufacturer's optimal pricing strategies and a scheme for reducing carbon emissions are derived. Secondly, our article examines TOR programs with carbon tax when there is a gap between consumers' willingness to pay for remanufactured products and the durability of new products. Our results show that an increase in consumer willingness to pay and a decline in product durability can stimulate consumers to participate in TOR programs, thereby increasing corporate profits, while carbon emissions rebound, leading to higher carbon emissions. Finally, our article considers the impacts of government subsidies on TOR programs with carbon tax and consumer surplus. A scheme was developed to ensure that enterprises do not lose profits, yet reduce carbon emissions. Also, the optimal plan for government subsidies was derived through numerical examples. Additionally, our article shows that TOR programs with government subsidies and carbon tax can boost consumer surplus. As a consequence, our article contributes to insights in terms of consumers, management of enterprises, and the governments, facilitating their achievement of maximum profits from TOR with carbon tax.

The second part of our article presents the relevant literature. In Section 3, three models are introduced, namely, the TOR model without carbon tax, the TOR model with carbon tax, and the TOR model with carbon tax and government subsidies. Model analyses and comparisons are provided in the fourth part. Section 5 shows numerical analyses to test the model. In Section 6, conclusions are drawn, and limitations and future research directions are described.

\section{Literature Review}

\subsection{Trade-Old-for-New (Remanufactured) Literature}

With the gradual maturity of the production form, remanufacturing is believed to be able to save manufacturing costs, which is conducive to improving market competitiveness, and it is being recognized by an increasing number of people. Therefore, a host of scholars have conducted research on remanufacturing. For example, Agrawal et al. (2016) show when and how to offer trade-in rebates to recycle old products to achieve better price discrimination and weaken competition from third-party remanufacturers (3PR). The authors show that although remanufactured products can cannibalize the sales of new products, it is still necessary for a company to provide remanufactured products to prevent 3PR from entering the market [15]. Zhu et al. (2016) compare two enterprises that implemented/did not implement "trade-in" in a duopoly environment; then, a two-stage competitive environment is introduced to determine the trade-in threshold, and they concluded that the trade-in could bring a competitive advantage to the market share and profit of an enterprise [16]. Also, there is much literature examining remanufactured products and the pricing and production strategies of TON (Yan et al., 2017; Xiao 2017; Miao et al., 2017; Liu et al., 2018; Liu et al., 2018; Cao et al., 2018; Huang 2018) [17-23]. For instance, Miao et al. (2017) developed three closed-loop supply chain (CLSC) decision models for TON: concentrated recycling, recycling by retailers, and recycling by manufacturers. Based on 
the assessment of life cycles, the study shows that TON can boost the environmental performance of the CLSC system, and that trade-in strategies can be used to stimulate consumer demand and boost profits for manufacturers and retailers only if the direct net value of a used product is high enough [19]. Cao et al. (2018) show the best trade-in strategy for enterprises using B2C platforms with self-owned stores or a third-party store retail model. They discuss how businesses can offer trade-in rebates to consumers with gift cards (GC) or cash coupons (CC), and they find that GC and CC are not always good for the platform [22]. The literature contributes to a good understanding of TON, while there is little literature on TOR pricing and production strategies. For example, Han et al. (2017) examine the status of TOR programs operated by companies when there is a large difference between consumer acceptance of remanufactured products and the durability of new products. Their study shows that a rise in government subsidies and a drop in durability can stimulate consumers to participate in TOR programs, and the involvement of TOR programs can increase recycling rates of products [7]. For a scenario in which TON and TOR coexist, Ma et al. (2017) explore the optimal pricing decisions of enterprises and determine the threshold at which enterprises should provide TON and TOR, and they discuss the optimal strategies for enterprises if government subsidies are subject to budget limits [8]. For the case of cannibalization between new products and remanufactured products, Zhu and Wang (2018) look into the optimal pricing strategies for mixed trade in TON and TOR supply chains [24].

The literature above includes each perspective of TON programs, showing that remanufacturing and TON are conducive to improving market competitiveness, and obtaining the optimal production decision of the manufacturer under different circumstances, which greatly contributes to remanufacturing and TON practices. However, much of the prior research has focused on TON, and there is little literature on TOR. Despite this, the studies have contributed to a better understanding of TOR. The manufacturing process will inevitably generate carbon emissions, resulting in serious environmental problems. Due to pressing environmental concerns, the regulation of carbon emissions is essential to decreasing the emissions caused by manufacturing and remanufacturing. So far, there has been little literature considering carbon emissions in the process of TOR. Therefore, the examination of the profits and carbon emissions of TOR enterprises with subsidies and carbon tax differentiates this article from others.

\subsection{Low Carbon}

Much research on carbon emissions constraints, carbon tax, and carbon cap-and-trade has addressed carbon reduction, pricing strategies, sustainable supply chains, corporate profits, and social welfare (Yang et al., 2018; Hovelaque et al., 2015; Xu et al., 2016; Yang et al., 2017; Ji et al., 2017; Wang et al., 2017; Yuan et al., 2018; Wang et al., 2018; Wang et al., 2018; Cheng et al., 2018; Liu et al., 2018) [1,2,13,25-32]. To illustrate, Hovelaque and Mazahir (2015) look at the economic order quantity (EOQ) model with carbon constraints and ensure that enterprises can achieve a win-win outcome with regard to profits and carbon emissions [2]. Xu et al. (2017) study the joint production and pricing issues of multiproduct manufacturing enterprises under the regulations of cap-and-trade and carbon tax, and compare the impact of the two regulations on total carbon emissions, corporate profits, and social welfare [13]. Extensive literature on carbon constraints, carbon taxes, and carbon cap-and-trades concerns the mechanisms for reducing carbon emissions and the production decisions of enterprises. However, since remanufacturing can save manufacturing costs and reduce carbon emissions, some scholars focus on the production and pricing decisions of low-carbon supply chains in the context of remanufacturing. Yenipazarli et al. (2016) and Yang et al. (2017) explore the optimal production and pricing strategies of new and remanufactured products with carbon tax, considering profits and environmental issues arising from remanufacturing [33,34]. In terms of empirical studies, Saxena et al. (2018) collected data on tire remanufacturing in India and developed a model of tire remanufacturing supply chains by integrating the economy, carbon emission targets, and the carbon tax policy for making a decision on the technological investment required for a reduction in carbon emissions [35]. He (2018) proposes a new integrated supplier selection hybrid model comprising factor 
analysis (FA), data envelopment analysis (DEA), and analytic hierarchy process (AHP), namely, the FA-DEA-AHP. The model was used to study seven cement suppliers of a large industrial enterprise. The results show that this method not only selects effective suppliers, but also achieves comprehensive ordering. It provides a theoretical value for selecting excellent low-carbon suppliers and establishing an efficient low-carbon supply chain [36]. Additionally, in light of carbon tax and consumer preference for low carbon, Zhang et al. (2018) investigated the pricing strategy of a manufacturer's recycling and remanufacturing processes; they considered consumers but neglected product durability [37]. Zhou et al. (2018) examine a model that assessed the impacts of the quality uncertainty of recycled products on carbon emissions, and show that the consideration of quality uncertainty can increase profits effectively and decrease total carbon emissions [38]. By differentiating between new and remanufactured products and by depicting the optimal carbon tax in a two-stage model of production decisions, Wang et al. (2018) show that a rational choice of carbon tax can stimulate manufacturers to invest in technology for carbon reduction and remanufacturing [39]. Turki et al. (2018) analyzed the optimal inventory and manufacturing/remanufacturing strategies by taking several factors into account: the differences between new and remanufactured products, random machine failures, carbon constraints, and different random customers' demand for these two types of commodities. Their results show that set-up costs, return rates, and machine availability have a significant impact on inventory and production plans for new and remanufactured products, and that lower carbon caps or higher carbon trading prices encourage producers to recycle and remanufacture waste items and curb carbon emissions [40].

In summary, the extant literature on low-carbon remanufacturing is conducive to enhancing corporate profits and environmental performance, as it sheds light on the optimal allocation of supply chains and the performance of enterprises and environment under carbon emission regulation and provides guidance for reducing carbon emissions. Nevertheless, these studies have ignored consumer willingness to pay and product durability, and they fail to discuss TOR with carbon tax. To fill this gap and curb carbon emissions, this article focuses on TOR with carbon tax by considering the discrepancy between consumer willingness to pay and product durability. Consequently, the contribution of this article resides in the discussion of the benefits for enterprises, society, and the environment resulting from TOR programs with carbon tax.

\subsection{Government Subsidies}

Hu et al. (2016) discuss the impacts of allocating carbon quotas and government subsidies on a manufacturer's profits and recycling rates in the closed-loop supply chain and demonstrate that the combination of these two methods can boost recycling activity and reduce carbon emissions [41]. Miao et al. (2016) resolved the issue of TON with regulated carbon emissions and analyzed the manufacturer's optimal pricing and production decisions following the plans for carbon tax and carbon cap-and-trade. They show that well-designed government subsidies can reduce the total carbon emissions, without affecting a manufacturer's profits [6]. Shu et al. (2017) examine the optimal production strategies with remanufacturing subsidies and tax reimbursement, and their results show that TON subsidies can encourage customers to purchase new and remanufactured products to replace their existing products. Remanufacturing subsidies and tax reimbursement are advantageous to the manufacturer, facilitating further development of remanufacturing [10]. Hazen et al. (2017) integrated the price factor, government incentives, environmental benefits, and the regulating effect of consumer attitudes to investigate the consumer's intention of shifting from purchasing new products to buying remanufactured products. The results show that the consumer's attitude toward remanufactured products can be a key moderating factor in decisions for changing products [42]. Zhang et al. (2018) study the impacts of carbon trade and subsidies on carbon emissions and corporate profits in closed-loop remanufacturing supply chains. Their results show that when the price of carbon trade and government subsidies satisfy certain conditions, a combination of carbon 
trade and subsidies can lower the retail price and increase recycling rates and demand, boosting the total profits of supply chains dramatically and reducing carbon emissions at the same time [43].

In terms of government subsidies, a large number of scholars argue that government subsidies can increase the well-being of enterprises and society, thus playing a pivotal role in reducing carbon emissions, which can stimulate consumers to buy remanufactured products. So, adding government subsidies to the carbon tax and TOR could increase corporate profits while reducing emissions. In addition, since TOR rebates can be the amount received by consumers to refund an old product, they must be considered when implementing TOR. Thus, we consider TOR rebates and the impact of TOR on the environment and corporate profits when government subsidies and carbon tax policies are applied. Under this circumstance, this article shows that optimal pricing strategies and corporate profits of enterprises rest on remanufacturing costs and emissions efficiency, as well as carbon tax and government subsidies. Therefore, this article investigates the optimal decisions under a TOR program with carbon tax and subsidies. This paper is also compared with the relevant TON(TOR) literature, as shown in Table 1.

Table 1. Comparison between this article and the literature on trade-old-for-new (TON) (trade-oldfor-remanufactured (TOR)).

\begin{tabular}{|c|c|c|c|c|c|}
\hline Literature & $\begin{array}{l}\text { Remanufacturing Pricing } \\
\text { and Production Decisions }\end{array}$ & TON & TOR & $\begin{array}{l}\text { Carbon } \\
\text { Tax }\end{array}$ & $\begin{array}{l}\text { Government } \\
\text { Subsidies }\end{array}$ \\
\hline Yan et al. (2017) [17] & & $\sqrt{ }$ & & & \\
\hline Xiao et al. (2017) [18] & $\sqrt{ }$ & $\sqrt{ }$ & & & \\
\hline Miao et al. (2017) [19] & & $\sqrt{ }$ & & & \\
\hline Liu et al. (2018) [20] & $\sqrt{ }$ & $\sqrt{ }$ & & & \\
\hline Liu et al. (2018) [21] & $\sqrt{ }$ & $\sqrt{ }$ & & & \\
\hline Cao et al. (2018) [22] & & $\sqrt{ }$ & & & \\
\hline Huang et al. (2018) [23] & & $\sqrt{ }$ & & & \\
\hline Han et al. (2017) [7] & $\sqrt{ }$ & & $\sqrt{ }$ & & $\sqrt{ }$ \\
\hline Ma et al. (2017) [8] & $\sqrt{ }$ & & $\sqrt{ }$ & & \\
\hline Zhu et al. (2018) [24] & $\sqrt{ }$ & & $\sqrt{ }$ & & \\
\hline Miao et al. (2016) [6] & $\sqrt{ }$ & $\sqrt{ }$ & & $\sqrt{ }$ & $\sqrt{ }$ \\
\hline This article & $\sqrt{ }$ & & $\sqrt{ }$ & $\sqrt{ }$ & $\sqrt{ }$ \\
\hline
\end{tabular}

\section{Parameter Setting in the Model}

The key feature of our article lies in an enterprise which aims to maximize its profits and sells durable goods to the market, depending on carbon tax and government subsidies. Enterprises determine whether the manufacturer or remanufacture on the basis of consumers' willingness to pay for remanufactured products and the durability of new products. They also determine their optimal production strategies according to carbon tax and government subsidies to maximize their profits and curb carbon emissions. In the light of the existing literature, below are some assumptions.

\subsection{Enterprises and Products}

It is assumed that enterprises can manufacture new products with fresh raw materials, and they may make remanufactured products using waste products. The unit costs of making new and remanufactured products are $c$ and $c_{r}$, respectively. The life cycle of new products consists of two stages, with the first stage for new products and the second stage for used products. The life cycle of remanufactured products is one stage. The enterprise provides new and remanufactured products at unit prices of $p_{1 n}$ and $p_{2 r}$ in turn in the first and second stages (if TOR programs are implemented). TOR consumers gain a discount of $p_{u}$. To make remanufacturing profitable, it is assumed that the production cost of new products is higher than that of remanufactured products, and the discount TOR consumers get is lower than the cost of remanufactured products; hence, $p_{u}<c_{r}<c$. The government provides a subsidy of $s$ for consumers involved in TOR programs. Additionally, carbon emissions from making a unit of a new and remanufactured product are $e_{n}\left(e_{n}>0\right)$ and $e_{r}\left(e_{r}>0\right)$, respectively. The tax rate levied by the government per unit carbon emission is $t$, and thus, the cost of the carbon emissions to enterprises for each unit of new (remanufactured) product made is $e_{n} t\left(e_{r} t\right)$. 


\subsection{Consumers}

In the first stage, the size of the potential consumer population in the market is $\Phi$. Consumers have not purchased products from the enterprise previously, and they decide to buy new products because of the utility of the product. If the consumers purchase products from the enterprise in the first stage, they have three options in the second stage. (1) They buy new products. However, this is almost the same as the consumer directly purchasing new products. Therefore, it is believed that consumers in this segment purchase new products in the first stage. (2) They replace used products with remanufactured products: namely, they participate in TOR programs. (3) They continue using old products. To maintain focus, other circumstances are not considered, such as TON and directly purchasing remanufactured products.

The utility which new products bring to consumers is $\theta$. Heterogeneity exists among consumers, and hence, $\theta$ is subject to $U(\bar{\theta}, \underline{\theta})$ in an even distribution, where $\bar{\theta}=0, \underline{\theta}=1$. In the second stage, the utility of used products to consumers is $\beta \theta$, where $\beta$ is the durability of new products, reflecting the reserve value of used products after the first stage. The utility of remanufactured products to consumers is $\alpha \theta$, where $\alpha(0<\alpha<1)$ denotes consumers' willingness to pay for remanufactured products.

In terms of consumers, the utility of remanufactured products is higher than that of used products but lower than that of new products; hence, assume $0<\beta<\alpha<1$, which is in line with prior literature (Souza 2013; Han 2017) [8,44]. In the first stage, consumers determine whether they purchase new products or not on the basis of the product utility. In the second stage, consumers decide whether they replace their existing products or not (continuing to use old products or participating in TOR programs). Every consumer can only have one product, at most, each time.

\subsection{Decision Processes}

This article focuses on a two-stage Stackelberg game model consisting of manufacturers, retailers, and consumers. According to the optimal responses of consumers and retailers, the wholesale prices and production of new and remanufactured products are confirmed. Based on the optimal responses of manufacturers and consumers, retail prices of new and remanufactured products are confirmed. Consumers make purchasing decisions on the basis of responses from manufacturers and retailers, and consumer demand amounts to the manufacturer's production. The target of enterprises is to maximize the total profits in the first and second stages. It is assumed that the discount factor in the second stage is $\delta(0<\delta<1)$. For stability and equilibrium, common parameters are developed in the model of durable goods in multiple stages (Agrawal and Thomas 2012; Han et al., 2017) [7,45]. Table 2 shows specific parameters and their meanings.

Table 2. Parameter notations.

\begin{tabular}{ll}
\hline Given Parameters & \\
\hline$\Phi$ & Potential consumer scale in the market \\
$\theta$ & Consumer evaluation of new products \\
$\alpha(0<\alpha<1)$ & Consumers' willingness to pay for remanufactured products \\
$\beta(0<\beta<\alpha<1)$ & Durability of new products, reflecting the reserved value of used products after the first stage \\
$\delta(0<\delta<1)$ & Discount coefficient of net present value \\
$c$ & unit production cost of new products \\
$c_{r}$ & Unit remanufacturing cost of remanufactured products \\
$s$ & TOR subsidies for consumers with government carbon tax \\
$p_{u}\left(p_{u}<c_{r}<c\right)$ & TOR rebates \\
$e_{n}\left(e_{n}>0\right)$ & Carbon emissions from manufacturing per new product \\
$e_{r}\left(e_{r}>0\right)$ & Carbon emissions from manufacturing per remanufactured product \\
$t(0<t<1)$ & Carbon tax rate levied by the government \\
$e_{n} t\left(e_{r} t\right)$ & Cost of carbon emissions from manufacturing per new (remanufactured) product \\
\hline Decision Parameters & \\
\hline$p_{i j}$ & Prices of Product $j$ in Stage $i(i=1,2 ; j=n:$ new products; $r$ remanufactured products) \\
$q_{i j}$ & Production of Product $j$ in Stage $i(i=1,2 ; j=n:$ new products; $r$ remanufactured products) \\
$U$ & Utility achieved by consumers purchasing/using products \\
$\Pi$ & Profit function \\
Upper $t^{*}, t s^{*}$ & Optimal strategies in TOR programs without carbon tax, with carbon tax policy, and with carbon tax and subsidies \\
\hline
\end{tabular}




\section{Analyses and Comparisons in the Model}

Initially, TOR programs without carbon tax are explored. TOR has already been studied by Han et al. (2017) [7], which serves as the reference for the model built in our study. The TOR program without carbon tax is the reference model for drawing the optimal strategy to distinguish between the impacts of carbon tax and government subsidies on enterprises, society, and the environment. Subsequently, models and solutions of TOR programs with carbon tax and TOR programs with carbon tax and government subsidies are used for deriving the optimal prices and production strategies of new and remanufactured products. Finally, the primary research question of how TOR programs with carbon tax policy and government subsidies affect enterprises, the environment, and society is addressed. Our article compares these two schemes to understand their impacts on enterprises, the environment, and social performance and achieve optimal strategies.

\subsection{Reference Model: TOR Program without Carbon Tax}

In the first stage, enterprises supply new products, and in the second stage, they offer remanufactured products. When the utility to consumers is $U_{1 n}=\theta-p_{1 n}>0$ in the first stage, consumers purchase new products. In the second stage, (1) if consumers directly purchase new products, this is the same as those directly buying new products in the first stage. Therefore, these consumers can be considered those who buy new products in the first stage. (2) The utility gained by consumers in TOR programs is $U_{2 r}=\alpha \theta-\left(p_{2 r}-p_{u}\right)$. (3) The utility gained by consumers who continue using old products is $U_{2 u}=\beta \theta$. In the second stage, when $U_{2 r} \succ U_{2 u} \succ 0$, consumers tend to participate in TOR programs; otherwise, consumers continue using old products or directly purchase new products. Consequently, Figure 1 shows that consumers in TOR programs without a carbon tax policy are subdivided.

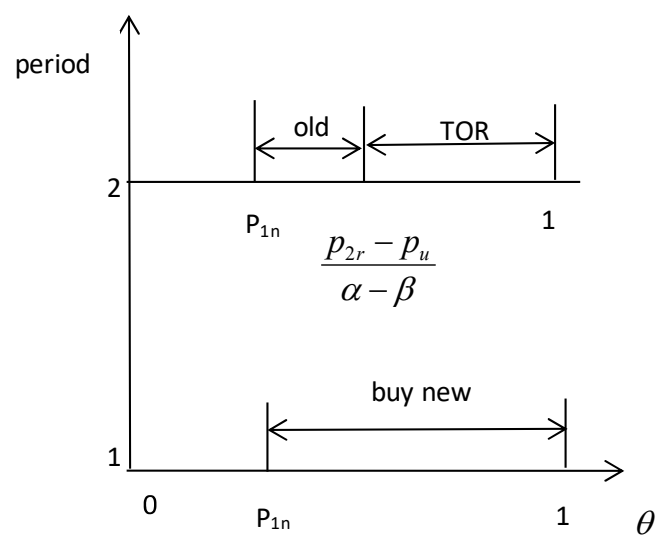

Figure 1. Consumer subdivision of the TOR scheme without carbon tax.

The target of enterprises is to maximize total profits of closed-loop supply chains in the first and second stages, and hence, Model (1) is established as follows.

$$
\begin{array}{r}
\underset{p_{1 n}, p_{2 r}}{\operatorname{Max} \Pi=} \phi \\
\text { s.t }\left\{\begin{array}{c}
\alpha-\beta-\left(p_{2 r}-p_{u}\right) \geq 0 \\
p_{1 n}\left(p_{1 n}-c\right) d \theta+\delta \phi \int_{\frac{2}{2 r}-p_{u}}^{1}\left(p_{2 r}-p_{1 n}(\alpha-\beta) \geq 0\right.
\end{array}\right.
\end{array}
$$

wherein profits in the first and second stages are $\phi \int_{p_{1 n}}^{1}\left(p_{1 n}-c\right) d \theta$ and $\delta \varphi \int \frac{p_{2 n}-p_{u}}{1-\beta}\left(p_{2 n}-c\right) d \theta$, respectively. The constraints ensure that the consumers in TOR programs in the second stage have already purchased products in the first stage, and the quantity must not be negative and must be fewer than the number of consumers in the first state. Proposition 1 can be derived from the solutions in Model (1). Proof of Proposition 1, other propositions, and corollaries can be found in Appendix A. 
Proposition 1. In TOR programs without carbon tax, enterprises have three optimal strategies based on the discrepancy between consumers' willingness to pay $\alpha$ for remanufactured products and the durability $\beta$ of new products. Table 3 shows the details.

Table 3. Optimal prices, production, and profits of enterprises in TOR programs with carbon tax.

\begin{tabular}{|c|c|c|c|}
\hline Case & N1 & N2 & N3 \\
\hline Conditions & $\beta+c_{r}-p_{u} \leq \alpha, \beta \geq \alpha-\frac{c_{r}-p_{u}}{c}$ & $\alpha \leq \beta+c_{r}-p_{u}, \beta \geq \alpha-\frac{c_{r}-p_{u}}{c}$ & $\alpha \geq \beta+c_{r}-p_{u}, \beta \leq \alpha-\frac{c_{r}-p_{u}}{c}$ \\
\hline \multirow{2}{*}{ Price } & $P_{1 n}^{n t *}=\frac{1+c}{2}$ & $P_{1 n}^{*}=\frac{1+c}{2}$ & $p_{1 n}^{*}=\frac{1+c+\delta\left(\alpha-\beta+c_{r}-p_{u}\right)}{2+2 \delta(\alpha-\beta)}$ \\
\hline & $p_{2 r}^{*}=\frac{\alpha-\beta+c_{r}+p_{u}}{2}$ & $p_{2 r}^{*}=\alpha-\beta+p_{u}$ & $p_{2 r}^{*}=\frac{(\alpha-\beta)\left(1+c+\delta\left(\alpha-\beta+c_{r}+p_{u}\right)\right)+2 p_{u}}{2+2 \delta(\alpha-\beta)}$ \\
\hline \multirow{2}{*}{ Quantity } & $q_{1 n}^{*}=\frac{1-c}{2}$ & $q_{1 n}^{*}=\frac{1-c}{2}$ & $q_{1 n}^{*}=\frac{1-c+\delta\left(\alpha-\beta-c_{r}+p_{u}\right)}{2 \delta(\alpha-\beta)+2}$ \\
\hline & $q_{2 r}^{*}=\frac{\alpha-\beta-c_{r}+p_{u}}{2(\alpha-\beta)}$ & $q_{2 r}^{*}=0$ & $q_{2 r}^{*}=\frac{1-c+\delta\left(\alpha-\beta-c_{r}+p_{u}\right)}{2 \delta(\alpha-\beta)+2}$ \\
\hline Profit & $\Pi^{n t *}=\frac{\delta \phi\left(\alpha-\beta-c_{r}+p_{u}\right)^{2}}{4(\alpha-\beta)}+\frac{\phi(1-c)^{2}}{4}$ & $\Pi^{n t *}=\frac{\phi(1-c)^{2}}{4}$ & $\Pi^{n t *}=\frac{\phi\left(1-c+\delta\left(\alpha-\beta-c_{r}+p_{u}\right)\right)^{2}}{4+4 \delta(\alpha-\beta)}$ \\
\hline Consumer & $\begin{array}{l}\text { Some consumers continue to use old } \\
\text { products or purchase new products. } \\
\text { Some consumers opt for } \\
\text { TOR programs. }\end{array}$ & $\begin{array}{l}\text { All consumers continue to use old } \\
\text { products or purchase new products. } \\
\text { No consumer opts for } \\
\text { TOR programs. }\end{array}$ & $\begin{array}{l}\text { No consumer purchases new products } \\
\text { or continues using old products. } \\
\text { All consumers opt for TOR programs. }\end{array}$ \\
\hline
\end{tabular}

Proposition 1 describes three optimal strategies for TOR programs without carbon tax. When the production cost of remanufactured products and TOR discounts are fixed, enterprises should make optimal decisions by matching the consumers' willingness to pay for remanufactured products with the durability of new products. In the three cases, consumers tend to purchase new products in the first stage. In the second stage, when consumers' willingness to pay for remanufactured products and the durability of new products are neutral (Case N1), some consumers purchase new products, and some consumers engage in TOR programs, while other consumers choose to continue using old products. When consumers' willingness to pay for remanufactured products is quite low and the durability of new products is extremely high (Case N2), some consumers purchase new products or continue using old products, while no consumers choose TOR programs. When consumers' willingness to pay for remanufactured products is quite high and the durability of new products is extremely low (Case N3), no consumers purchase new products or continue using old products. At this moment, all consumers choose TOR programs. These phenomena are in line with reality. This shows that consumers decide whether they engage in TOR programs depending on the durability of new products. A lower durability of new products encourages more consumers to participate in TOR programs, which is consistent with Han et al., 2017 [7]. Consequently, enterprises can rationally design for the durability of new products to prompt consumers to engage in TOR programs.

\subsection{TOR Scheme with Carbon Tax}

This part considers the impacts of a carbon tax policy on the optimal strategies of enterprises. The government imposes a carbon tax per unit of carbon emission from the processes of making new and remanufactured products. Consumers make purchasing decisions depending on the utility of new and remanufactured products, and the subdivision of consumers is the same as that in a TOR program without a carbon tax policy. Like the model in Section 4.1, the optimal Model (2) strategy of enterprises with carbon tax is constructed as follows. Proposition 2 is derived from the solutions of Model (2).

$$
\begin{gathered}
\underset{p_{1 n}, p_{2 r}}{\operatorname{Max}} \Pi=\phi \int_{p_{1 n}}^{1}\left(p_{1 n}-c\right) d \theta+\delta \phi \int_{\frac{p_{2 r}-p_{u}}{\alpha-\beta}}^{1}\left(p_{2 r}-c_{r}\right) d \theta-\left(e_{n} q_{1 n} t+e_{r} q_{2 r} t\right) \\
\text { s.t }\left\{\begin{array}{c}
\alpha-\beta-\left(p_{2 r}-p_{u}\right) \geq 0 \\
p_{2 r}-p_{u}-p_{1 n}(\alpha-\beta) \geq 0
\end{array}\right.
\end{gathered}
$$

Proposition 2. In TOR programs with a carbon tax policy, enterprises possess three optimal strategies on the basis of the discrepancy between consumers' willingness to pay $\alpha$ for remanufactured products and the durability $\beta$ of new products. Table 4 shows the details. 
Table 4. Optimal prices, production, and profits of enterprises in TOR programs with carbon tax.

\begin{tabular}{|c|c|c|c|}
\hline Case & N1 & N2 & N3 \\
\hline Conditions & $\beta+c_{r}-p_{u} \leq \alpha, \beta \geq \alpha-\frac{c_{r}-p_{u}}{c}$ & $\alpha \leq \beta+c_{r}-p_{u}, \beta \geq \alpha-\frac{c_{r}-p_{u}}{c}$ & $\alpha \geq \beta+c_{r}-p_{u}, \beta \leq \alpha-\frac{c_{r}-p_{u}}{c}$ \\
\hline \multirow{2}{*}{ Price } & $P_{1 n}^{t *}=\frac{\phi(1+c)+e_{n} t}{2 \phi}$ & $P_{1 n}^{t *}=\frac{\phi(1+c)+e_{n} t}{2 \phi}$ & $p_{1 n}^{t *}=\frac{\phi(1+c)+\left(e_{n}+e_{r}\right) t+\delta \phi\left(\alpha-\beta+c_{r}-p_{u}\right)}{2 \phi[\delta(\alpha-\beta)+1]}$ \\
\hline & $p_{2 r}^{t *}=\frac{\delta \phi\left(\alpha-\beta+c_{r}+p_{u}\right)+e_{r} t}{2 \delta \phi}$ & $p_{2 r}^{t *}=\alpha-\beta+p_{u}$ & $p_{2 r}^{t *}=\frac{\left(\phi(1+c)+\left(e_{n}+e_{r}\right) t+\delta \phi\left(\alpha-\beta+c_{r}+p_{u}\right)\right)(\alpha-\beta)+2 \phi p_{u}}{2 \phi[\delta(\alpha-\beta)+1]}$ \\
\hline \multirow{2}{*}{ Quantity } & $q_{1 n}^{t *}=\frac{\phi(1-c)-e_{n} t}{2 \phi}$ & $q_{1 n}^{t *}=\frac{\phi(1-c)-e_{n} t}{2 \phi}$ & $q_{1 n}^{t *}=\frac{\phi(1-c)-\left(e_{n}+e_{r}\right) t+\delta \phi\left(\alpha-\beta-c_{r}+p_{u}\right)}{2 \phi[\delta(\alpha-\beta)+1]}$ \\
\hline & $q_{2 r}^{t *}=\frac{\delta \phi\left(\alpha-\beta-c_{r}+p_{u}\right)-e_{r} t}{2 \delta \phi(\alpha-\beta)}$ & $q_{2 r}^{t *}=0$ & $q_{2 r}^{t *}=\frac{\phi(1-c)-\left(e_{n}+e_{r}\right) t+\delta \phi\left(\alpha-\beta-c_{r}+p_{u}\right)}{2 \phi[\delta(\alpha-\beta)+1]}$ \\
\hline Profit & $\begin{array}{l}\Pi^{t *}=\frac{\left[\delta \phi\left(\alpha-\beta-c_{r}+p_{u}\right)\right]^{2}-\left(e_{r} t\right)^{2}}{4 \delta \phi(\alpha-\beta)} \\
+\frac{(\phi(1-c))^{2}-\left(e_{n} t\right)^{2}}{4 \phi}-\frac{\left[\phi(1-c)-e_{n} t\right] e_{n} t}{2 \phi} \\
-\frac{\left[\delta \phi\left(\alpha-\beta-c_{r}+p_{u}\right)-e_{r} t\right] e_{r} t}{2 \delta \phi(\alpha-\beta)}\end{array}$ & $\Pi^{t *}=\frac{\left(\phi(1-c)-e_{n} t\right)^{2}}{4 \phi}$ & $\Pi^{t *}=\frac{\left(\phi(1-c)-\left(e_{n}+e_{r}\right) t+\delta \phi\left(\alpha-\beta-c_{r}+p_{u}\right)\right)^{2}}{4 \phi(\delta(\alpha-\beta)+1)}$ \\
\hline Consumer & $\begin{array}{l}\text { Some consumers use old products or } \\
\text { purchase new products. } \\
\text { Some consumers opt for TOR programs. }\end{array}$ & $\begin{array}{l}\text { All consumers use old products } \\
\text { or purchase new products. } \\
\text { No consumer opts for } \\
\text { TOR programs. }\end{array}$ & $\begin{array}{l}\text { No consumer purchases new products or } \\
\text { continues using old products. } \\
\text { All consumers opt for TOR programs. }\end{array}$ \\
\hline
\end{tabular}

Proposition 2 depicts three optimal strategies for TOR enterprises with a carbon tax policy. With a carbon tax policy, when the production cost of remanufactured products and TOR discounts are certain, the optimal strategies of enterprises are associated with consumers' willingness to pay for remanufactured products, the durability of new products, and the carbon tax policy. In Case N2, consumers do not engage in TOR programs, and thus, enterprises need to decide whether they make remanufactured products after matching consumers' willingness to pay for remanufactured products and the durability of new products. The next step is determining the optimal prices, production, and profits of new and remanufactured products according to the carbon tax policy.

\subsection{TOR Scheme with Carbon Tax and Government Subsidies}

This part considers the impacts of a carbon tax policy and government subsidies on the optimal strategies of enterprises. The government imposes carbon tax on carbon emissions from the processes of making new and remanufactured products. Meanwhile, the government provides subsidies for consumers who participate in TOR programs with carbon tax. Consumers make purchasing decisions based on the utility of new and remanufactured products, and the subdivision of consumers is the same as that in TOR programs without a carbon tax policy. Like the model in Section 4.1, the optimal Model (3) strategy of enterprises with carbon tax and government subsidies is defined as follows. Proposition 3 is derived from the solutions of Model (3).

$$
\begin{aligned}
& \underset{p_{1 n}, p_{2 r}}{\operatorname{Max}} \Pi=\phi \int_{p_{1 n}}^{1}\left(p_{1 n}-c\right) d \theta+\delta \phi \int_{\frac{p_{2 r}-p_{u}-s}{\alpha-\beta}}^{1}\left(p_{2 r}-c_{r}\right) d \theta-\left(e_{n} q_{1 n} t+e_{r} q_{2 r} t\right) \\
& \text { s.t }\left\{\begin{array}{c}
\alpha-\beta-\left(p_{2 r}-p_{u}-s\right) \geq 0 \\
p_{2 r}-p_{u}-s-p_{1 n}(\alpha-\beta) \geq 0
\end{array}\right.
\end{aligned}
$$

Proposition 3. In TOR programs with carbon tax and government subsidies, enterprises have three optimal strategies in the light of the discrepancy between consumers' willingness to pay $\alpha$ for remanufactured products and the durability $\beta$ of new products. Table 5 shows the details.

Proposition 3 provides three optimal strategies for TOR programs with carbon tax and government subsidies, whose results are similar to Proposition 2. When the production cost of remanufactured products and TOR discounts are fixed, the optimal strategies of enterprises are associated with consumers' willingness to pay for remanufactured products, the durability of new products, as well as the carbon tax policy and government subsidies. Corollary 5 analyzes how carbon tax and government subsidies affect TOR programs. 
Table 5. Optimal prices, production, and profits in the TOR programs with carbon tax and government subsidies.

\begin{tabular}{|c|c|c|c|}
\hline Case & N1 & N2 & N3 \\
\hline Conditions & $\beta+c_{r}-p_{u} \leq \alpha, \beta \geq \alpha-\frac{c_{r}-p_{u}}{c}$ & $\alpha \leq \beta+c_{r}-p_{u}, \beta \geq \alpha-\frac{c_{r}-p_{u}}{c}$ & $\alpha \geq \beta+c_{r}-p_{u}, \beta \leq \alpha-\frac{c_{r}-p_{u}}{c}$ \\
\hline \multirow{2}{*}{ Price } & $P_{1 n}^{t s *}=\frac{\phi(1+c)+e_{n} t}{2 \phi}$ & $P_{1 n}^{t s *}=\frac{\phi(c+1)+e_{n} t}{2 \phi}$ & $p_{1 n}^{t s *}=\frac{\phi(1+c)+\left(e_{n}+e_{r}\right) t+\delta \phi\left(\alpha-\beta+c_{r}-p_{u}-s\right)}{2 \phi \delta(\alpha-\beta)+1]}$ \\
\hline & $p_{2 r}^{t \mathrm{ts} *}=\frac{\delta \phi\left(\alpha-\beta+c_{r}+p_{u}+s\right)+e_{r} t}{2 \delta \phi}$ & $p_{2 r}^{t s *}=\alpha-\beta+p_{u}+s$ & $p_{2 r}^{t s *}=\frac{\left(\phi(1+c)+\left(e_{n}+e_{r}\right) t+\delta \phi\left(\alpha-\beta+c_{r}+p_{u}+s\right)\right)(\alpha-\beta)+2 \phi\left(p_{u}+s\right)}{2 \phi \delta(\alpha-\beta)+1]}$ \\
\hline \multirow{2}{*}{ Quantity } & $q_{1 n}^{t s *}=\frac{\phi(1-c)-e_{n} t}{2 \phi}$ & $q_{1 n}^{t s *}=\frac{\phi(1-c)-e_{n} t}{2 \phi}$ & $q_{1 n}^{t s *}=\frac{\phi(1-c)-\left(e_{n}+e_{r}\right) t+\phi \delta\left(\alpha-\beta-c_{r}+p_{u}+s\right)}{2 \phi \delta \delta(\alpha-\beta)+1]}$ \\
\hline & $q_{2 r}^{t s *}=\frac{\delta \phi\left(\alpha-\beta-c_{r}+p_{u}+s\right)-e_{r} t}{2 \delta \phi(\alpha-\beta)}$ & $q_{2 r}^{t s *}=0$ & $q_{2 r}^{t * *}=\frac{\phi(1-c)-\left(e_{n}+e_{r}\right) t+\phi \delta\left(\alpha-\beta-c_{r}+p_{u}+s\right)}{2 \phi[\delta(\alpha-\beta)+1]}$ \\
\hline Profit & $\begin{array}{l}\Pi^{t s *}=\frac{\left[\delta \phi\left(\alpha-\beta-c_{r}+p_{u}+s\right)\right]^{2}-\left(e_{r} t\right)^{2}}{4 \delta \phi(\alpha-\beta)} \\
+\frac{(\phi(1-c))^{2}-\left(e_{n} t\right)^{2}}{\left.4 \phi(1-c)-e_{n}\right] e_{n} t} \\
-\frac{\left[\delta \phi\left(\alpha-\beta-c_{r}+p_{u}+s\right)-e_{r} t\right] e_{r} t}{2 \phi \phi} \\
2 \delta \phi(\alpha-\beta)\end{array}$ & $\Pi^{t s *}=\frac{\left(\phi(1-c)-e_{n} t\right)^{2}}{4 \phi}$ & $\Pi^{t s *}=\frac{\left(\phi(1-c)-\left(e_{n}+e_{r}\right) t+\delta \phi\left(\alpha-\beta-c_{r}+p_{u}+s\right)\right)^{2}}{4 \phi(\delta(\alpha-\beta)+1)}$ \\
\hline Consumer & $\begin{array}{l}\text { Some consumers use old products or } \\
\text { purchase new products. } \\
\text { Some consumers opt for TOR programs. }\end{array}$ & $\begin{array}{l}\text { All consumers use old products } \\
\text { or purchase new products. } \\
\text { No consumer opts for } \\
\text { TOR programs. }\end{array}$ & $\begin{array}{l}\text { No consumer purchases new products or continues } \\
\text { using old products. } \\
\text { All consumers opt for TOR programs. }\end{array}$ \\
\hline
\end{tabular}

\subsection{Impacts on Enterprises of Discounts under TOR, Consumer Willingness to Pay, and Durability}

Corollary 1. It is not necessarily better if consumers' willingness to pay for remanufactured products is far higher, and it is not necessarily better if the durability of new products is much lower.

When enterprises implement TOR programs, it is vital that they design them for a fixed range of consumers' willingness to pay for remanufactured products and the durability of new products. If consumers' willingness to pay for remanufactured products is extremely high and the durability of new products is quite low (Case N3), all consumers only purchase remanufactured products. No consumers purchase new products, and hence, raw materials for remanufactured products may be insufficient. Also, if all consumers do not buy new products, this does not conform to reality. Additionally, if the durability of new products is very low, resulting in waste products being repetitively deployed for remanufactured products, that damages the environment imperceptibly. This provides insights for enterprises to make decisions. In other words, it is not necessarily better for consumers' willingness to pay for remanufactured products to be much higher, while it is not necessarily better for the durability of new products to be extremely lower.

Corollary 2. In Case N1 $\left(\beta+c_{r}-p_{u} \leq \alpha, \beta \geq \alpha-\frac{c_{r}-p_{u}}{c}\right)$, TOR programs are implemented. (1) The production and prices of remanufactured products and corporate profits increase with a rise in consumers' willingness to pay for remanufactured products. (2) The production and prices of remanufactured products and corporate profits grow with a rise in TOR rebates. (3) The production and prices of remanufactured products and corporate profits are stepped up with a drop in the durability of new products.

From Corollary 2(1), it is clear that a rise in consumers' willingness to pay for remanufactured products increases the production quantity and optimal selling prices of remanufactured products, as well as corporate profits. The reason is that consumers with a greater willingness to pay for remanufactured products (such as green consumers) are more willing to purchase remanufactured products. Therefore, enterprises may increase the production of remanufactured products, and they can raise the selling prices of remanufactured products appropriately to augment corporate profits. From Corollary 2(2), it is apparent that a rise in TOR rebates increases the production quantity and the optimal selling prices of remanufactured products, as well as corporate profits. A rise in TOR rebates results in a reduction in the real payment if consumers buy remanufactured products and the aim is attracting consumers to engage in TOR programs. Therefore, enterprises can boost the production quantity of remanufactured products. Under this circumstance, enterprises raise the selling price of remanufactured products, while consumers actually pay less. As a result, the demand for remanufactured products grows, contributing to greater profit for corporate enterprises. This finding 
provides insights into how the demand for remanufactured products is boosted. From Corollary 2(3), it is noticeable that the lower durability of new products can also attract consumers to engage in TOR programs, and therefore, the production quantity and selling prices of remanufactured products and corporate profits tend to rise. These findings shed light on consumer decision making so that management can determine what motivates consumers to purchase remanufactured products. Specifically, managers can raise consumers' willingness to pay for remanufactured products and TOR rebates while lowering the durability of new products to stimulate consumers' demand for remanufactured products.

\subsection{Impacts of Carbon Tax on Enterprises}

Corollary 3. (1) Prices of new and remanufactured products increase with a rise in carbon tax, while production quantity and corporate profits decline with a fall in carbon tax. (2) When $\delta e_{n}>e_{r}$, the price of new products is more sensitive to carbon tax than that of remanufactured products.

Corollary 3(1) shows that the prices of new and remanufactured products grow with a rise in carbon tax, while the production quantity of these two products and corporate profits decline with a rise in carbon tax. The reason is that, with a carbon tax policy, the cost of new and remanufactured products tends to be stepped up, leading to a rise in their wholesale prices. Hence, the prices of new and remanufactured products go up. In this way, the demand for new and remanufactured products drops. Consumers start to look for alternative products with a higher cost performance, leading to a drop in corporate profits. This finding offers a new insight into the pricing of new and remanufactured products. In other words, if enterprises impose a very high price on new and remanufactured products, they will lose a portion of customers. With a carbon tax policy, enterprises should bear some increase in production cost to increase the demand for new and remanufactured products, thereby boosting corporate profits and achieving win-win results together with consumers. In light of Corollary 3(2), when $\delta e_{n}>e_{r}$, the price of new products is more sensitive to that of remanufactured products. Carbon emissions caused by the manufacture of a new product are more than those from a remanufactured product, and therefore, the price of new products is more sensitive to that of a remanufactured product. That is to say, the price of new products increases more significantly than remanufactured products, leading to a dramatic decline in the demand for new products. As a result, the demand for remanufactured products is greater than that for new products. This shows that the manufacturer should decrease the production of new products, while increasing the production of remanufactured products.

\subsection{Impacts on Carbon Emissions of Carbon Tax, Consumer Willingness to Pay, and Durability}

Corollary 4. (1) The carbon emissions from making new and remanufactured products and the total carbon emissions from enterprises decline with a rise in carbon tax. (2) The total carbon emissions from enterprises increase with a rise in consumers' willingness to pay for remanufactured products, while they grow with a fall in the durability of new products.

Corollary 4(1) shows that carbon emissions from making new and remanufactured products and the total carbon emissions from enterprises tend to decline with a rise in carbon tax. The prices of new and remanufactured products tend to rise with a rise in carbon tax, leading to a drop in the production of these two kinds of products. As a result, carbon emissions from these products dwindle, with a reduction in the total carbon emission from enterprises. It is clear from Corollary 3(2) that a rise in prices of new products as a result of carbon tax is greater than that of remanufactured products, indirectly encouraging consumers to choose remanufactured products with lower prices. Consequently, the total carbon emission falls, as opposed to the case without a carbon tax policy. For this reason, this finding is insightful in that TOR programs with carbon tax can help reduce carbon emissions. It is 
obvious from Corollary 4(2) that the total carbon emission from enterprises increases with a rise in consumers' willingness to pay for remanufactured products, but with a decline in the durability of new products. TOR programs actually reduce consumer demand for new products, thereby cutting the total carbon emissions from enterprises. A very high consumer willingness to pay for remanufactured products and a very low durability of new products result in consumer demand for remanufactured products going up, and then carbon emission rebounds. This also shows that it is not necessarily better for consumers' willingness to pay for remanufactured products to be extremely high and for the durability of new products to be extremely low, in line with Corollary 1 . This finding shows that the total carbon emissions are stepped up if consumers' willingness to pay for remanufactured products rises and the durability of new products falls beyond a certain range. A rise in the demand for remanufactured products can lead to an increase in the manufacturer's profits, which benefits the manufacturer. Conversely, this change might not be advantageous to the government, and therefore, they can be controlled within a range, as discussed above, leading to a fall in carbon emissions.

\subsection{Impacts of Government Subsidies on Enterprises}

Corollary 5. The price, production quantity, and corporate profits of remanufactured products, carbon emissions from remanufactured products, and the total carbon emissions from enterprises increase with a rise in government subsidies.

The price the consumer pays for remanufactured products dwindles with a rise in government subsidies in TOR programs. Hence, a rise in a government subsidy can boost consumers' desire for remanufactured products, resulting in a rise in the demand for remanufactured products. Under this circumstance, even if the manufacturer increases the selling price of remanufactured products, the demand for remanufactured products does not fall. As a result, enterprises gain greater profits. However, new problems emerge. The carbon emission tends to be stepped up with a rise in the demand for remanufactured products, leading to a rise in the total carbon emission from enterprises. The government subsidy increases corporate profits and benefits consumers while damaging the environment. This is opposite to the primary purpose of government subsidies, and thus, government subsidies should be within a range. Numerical examples show the optimal program of government subsidies. Additionally, it is clear from Corollary 3 that a carbon tax may exert an enormous influence on the production of new and remanufactured products, whereas it can be seen from Corollary 5 that the government subsidy for TOR programs compensates for the demand for remanufactured products. Consequently, TOR programs with government subsidies and a carbon tax policy can have relatively greater impacts on new products, while exerting less influence on remanufactured products. This finding can be conducive to enterprises making certain production decisions, which can decrease the production of new products and correspondingly increase the production of remanufactured products.

The corollaries above depict that the production quantity, prices, corporate profits, and total carbon emissions of new and remanufactured products vary with carbon tax, consumers' willingness to pay for remanufactured products, the durability of new products, and government subsidies. Table 6 summarizes the monotony of these variables.

Table 6. Monotony of variables.

\begin{tabular}{lccccc}
\hline \multicolumn{1}{c}{ Variables } & $\begin{array}{c}\text { Production } \\
\text { of New } \\
\text { Products }\end{array}$ & $\begin{array}{c}\text { Production of } \\
\text { Remanufactured } \\
\text { Products }\end{array}$ & $\begin{array}{c}\text { Prices of } \\
\text { New } \\
\text { Products }\end{array}$ & $\begin{array}{c}\text { Prices of } \\
\text { Remanufactured } \\
\text { Products }\end{array}$ & $\begin{array}{c}\text { Profits of } \\
\text { Enterprises }\end{array}$ \\
\hline Carbon tax $\nearrow$ & $\searrow$ & $\searrow$ & $\nearrow$ & $\begin{array}{c}\text { Eotal Carbon } \\
\text { Enterprises }\end{array}$ \\
\hline $\begin{array}{l}\text { Consumers' willingness to pay } \\
\text { for remanufactured products } \nearrow\end{array}$ & $\rightarrow$ & $\nearrow$ & $\rightarrow$ & $\nearrow$ \\
\hline Durability of new products $\searrow$ & $\rightarrow$ & $\nearrow$ & $\rightarrow$ & $\nearrow$ & $\nearrow$ \\
\hline Government subsidies $\nearrow$ & $\rightarrow$ & $\nearrow$ & $\rightarrow$ & $\nearrow$ & $\nearrow$ \\
\hline
\end{tabular}




\subsection{Impacts of Carbon Tax on Consumer Surplus}

Corollary 6. With a carbon tax policy, in three cases - namely, directly purchasing new products, TOR programs, and TOR programs with government subsidies_consumer surplus is $\mathrm{CS}_{1 n}^{t}<C S_{2 r}^{t}<C S_{2 r}^{t s}$.

Consumer surplus denotes the gap between the maximum price consumers are willing to pay for certain products and the real prices of these products on the market. With a carbon tax policy, the following equations can be employed to express the consumer surplus in cases of directly purchasing new products, TOR programs, and TOR programs with government subsidies:

$$
\begin{gathered}
C S_{1 n}^{t}=\phi \int_{p_{1 n}^{t}}^{1}\left(\theta-p_{1 n}^{t}\right) d \theta+\delta \phi \int_{p_{1 n}^{t}}^{p_{2 r}^{t}} \beta \theta d \theta \\
C S_{2 r}^{t}=\phi \int_{p_{1 n}^{t}}^{1}\left(\theta-p_{1 n}^{t}\right) d \theta+\delta \phi\left(\int_{p_{1 n}^{t}}^{p_{2 r}^{t}} \beta \theta d \theta+\int_{p_{2 r}^{t}}^{1}\left(\alpha \theta-p_{2 r}^{t}+p_{u}\right) d \theta\right) \\
C S_{2 r}^{t s}=\phi \int_{p_{1 n}^{t}}^{1}\left(\theta-p_{1 n}^{t}\right) d \theta+\delta \phi\left(\int_{p_{1 n}^{t}}^{p_{2 r}^{t}} \beta \theta d \theta+\int_{p_{2 r}^{t}}^{1}\left(\alpha \theta-p_{2 r}^{t}+p_{u}+s\right) d \theta\right)
\end{gathered}
$$

Corollary 6 shows that consumer surplus is $C S_{1 n}^{t}<C S_{2 r}^{t}<C S_{2 r}^{t s}$. With a carbon tax policy, TOR rebates offset a portion of the prices of remanufactured products. As a result, when enterprises participate in TOR programs and the government provides subsidies for TOR programs, consumer surplus increases. TOR programs with government subsidies result in the maximum consumer surplus, and TOR programs rank second, with directly purchased new products ranking the last on the list. For this reason, TOR programs can increase consumer surplus, benefiting consumers. This finding sheds light on the purchasing decisions consumers make a with carbon tax policy in place, and consumers should engage in TOR programs to gain greater consumer surplus. Government subsidies can encourage consumers to purchase remanufactured products, contributing to greater consumer surplus.

\section{Numerical Examples}

The theoretical analyses of the optimal strategies under TOR programs are presented above. Subsequently, the numerical examples describe the optimal strategies, where $\phi=0.9, c=0.4$, $c_{r}=0.25, p_{u}=0.02, \delta=0.9, e_{n}=0.4, e_{r}=0.25$ are constant values, which are in line with the results in Miao et al. (2016) and Han et al. (2017) [6,7]. For meaningful and reasonable schemes, the variables $\alpha, \beta, t, s$ are changeable.

\subsection{Consumers' Willingness to Pay for Remanufactured Products}

Figure $2 \mathrm{a}$ assumes that $\beta=0.2, s=0.08, t=0.3$. In the three cases-namely, the case without a carbon tax policy, the case with a carbon tax policy, and the case with government subsidies and a carbon tax policy - the production quantity of remanufactured products increases with a rise in consumers' willingness to pay for remanufactured products, in line with Corollary 2(2). Clearly, it is likely that an increase in consumers' willingness to pay for remanufactured products will boost consumer demand for remanufactured products. Figure $2 b$ shows that, in the three cases-namely, the case without a carbon tax policy, the case with a carbon tax policy, and the case with government subsidies and a carbon tax policy-the prices of remanufactured products increase with a rise in consumers' willingness to pay for remanufactured products, in line with Corollary 2(1). The reason is that prices increase due to a rise in consumer demand for remanufactured products, in which $C_{t}$ denotes the carbon emissions from enterprises with a carbon tax policy, and $C_{t}^{s}$ denotes the carbon emissions from enterprises with a carbon tax policy and government subsidies. Figure $2 \mathrm{c}$ shows that profits and carbon emissions increase with a rise in consumers' willingness to pay for remanufactured 
products, in line with Corollaries 2(1) and 4(2). Also, government subsidies lead to a rise in demand for remanufactured products, and thus carbon emissions; profits for schemes with government subsidies are greater than those without government subsidies. Additionally, as consumers' willingness to pay for remanufactured products increases from 0.6 to 0.7 , carbon emissions rise from 0.118 to 0.138 , with a change of 0.02 , and the percentage of the impacts of consumers' willingness to pay for remanufactured products on carbon emissions is $20 \%$. This shows that carbon emissions increase with a rise in consumers' willingness to pay for remanufactured products. As a consequence, it is not necessarily better for consumers' willingness to pay for remanufactured products to be extremely high.

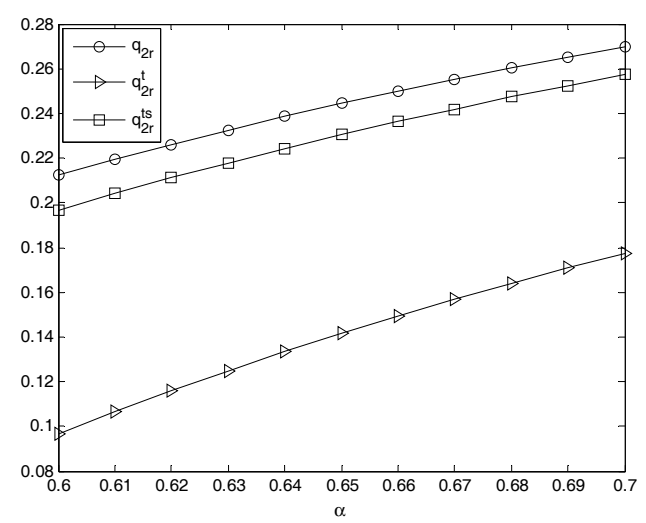

(a) Production of remanufactured products changes with consumers' willingness to pay $\alpha$ for remanufactured products.

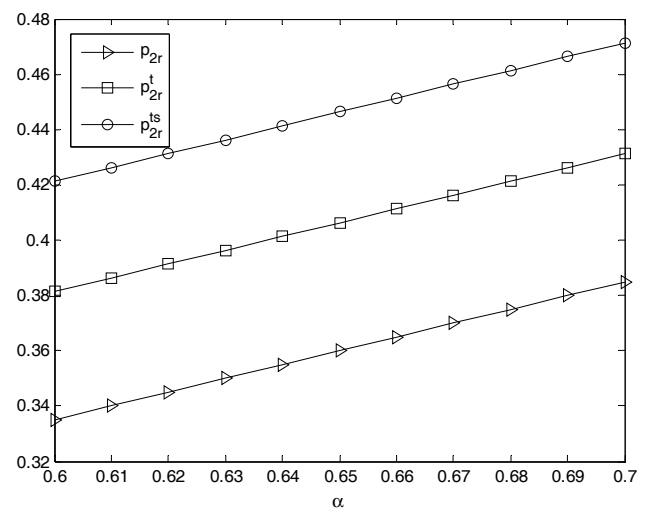

(b) Prices of remanufactured products change with consumers' willingness to pay $\alpha$ for remanufactured products.

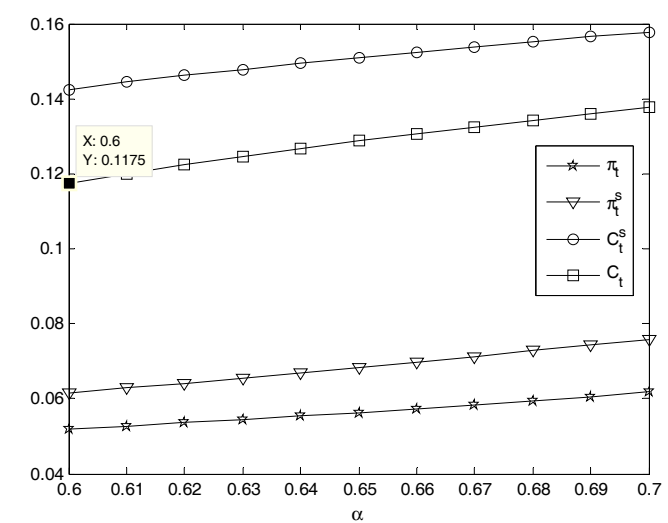

(c) Profits and carbon emissions of enterprises change with consumers' willingness to pay $\alpha$ for remanufactured products.

Figure 2. Impacts of consumers' willingness to pay $\alpha$ for remanufactured products on production, prices, profits, and carbon emissions of remanufactured products. 


\subsection{Durability of New Products}

Figure 3a assumes that $\alpha=0.8, s=0.08, t=0.5$. In the three cases-namely, the case without a carbon tax policy, the case with a carbon tax policy, and the case with government subsidies and a carbon tax policy-the production quantity of remanufactured products declines with a fall in the durability of new products, in line with Corollary 2(2). When $\beta>0.416$, with a carbon tax policy, the demand for remanufactured products can be negative as a result of the high durability of new products if carbon tax makes remanufactured products lose their advantage in cost. Obviously, enterprises can increase consumer demand for remanufactured products by reducing the durability of new products. Figure $3 \mathrm{~b}$ shows that, in the three cases-namely, the case without a carbon tax policy, the case with a carbon tax policy, and the case with government subsidies and a carbon tax policy-the prices of remanufactured products increase with a fall the in durability $\beta$ of new products, in line with Corollary 2(2). Prices are stepped up due to a rise in consumer demand for remanufactured products. Figure $3 \mathrm{c}$ shows that profits and carbon emissions increase with a fall in the durability of new products, in line with Corollaries 2(2) and 4(2). Government subsidies result in a rise in the demand for remanufactured products, and thus, carbon emissions and profits with government subsidies are greater than those without subsidies. Conversely, when the durability of new products is greater than 0.46 , consumers do not purchase remanufactured products without government subsidies, and all of them buy new products. Hence, corporate profits without government subsidies are greater than those with subsidies. Additionally, it can be seen from the figures that as the durability of new products decreases from 0.5 to 0.3 while carbon emissions increase from 0.032 to 0.047 , with a change of 0.015 , the percentage of the impacts from the durability of new products on carbon emissions is $7.5 \%$. This shows that carbon emissions increase with a fall in the durability of new products. As a result, it is not necessarily better for the durability of new products to be much lower.

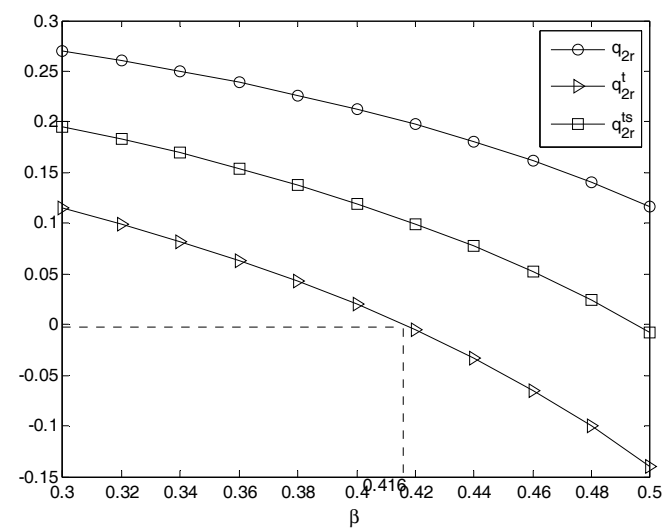

(a) Production of remanufactured products changes with the durability $\beta$ of new products.

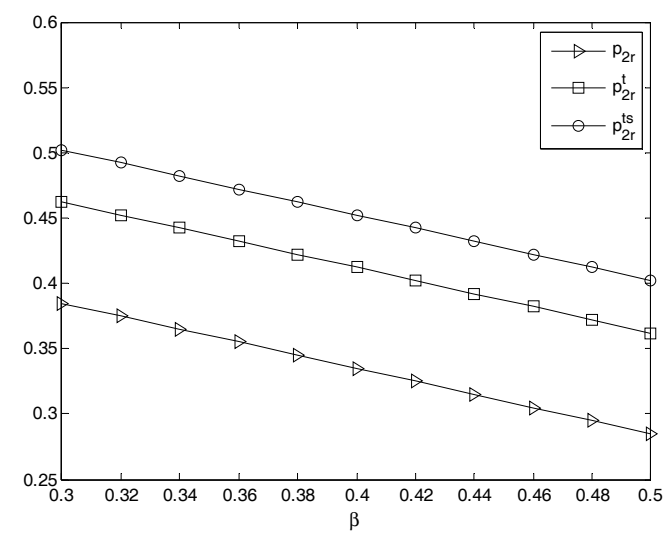

(b) Prices of remanufactured products change with the durability $\beta$ of new products.

Figure 3. Cont. 


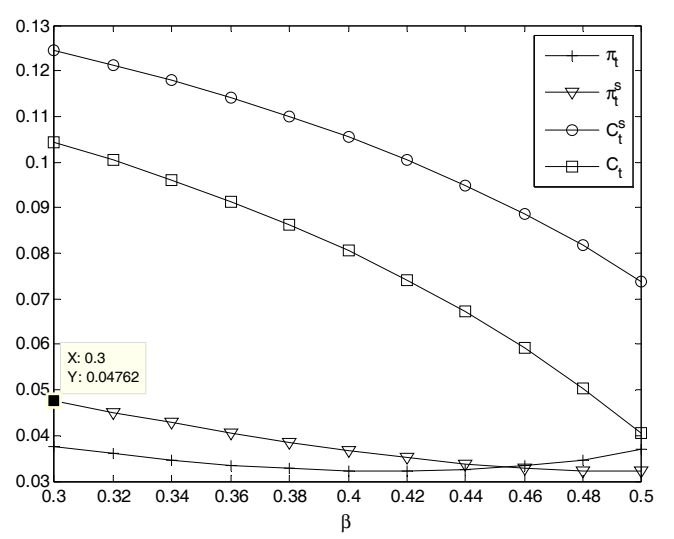

(c) Profits and carbon emissions of enterprises change with the durability $\beta$ of new products.

Figure 3. Impacts of changing the durability $\beta$ of new products on production, prices, profits, and carbon emissions of remanufactured products.

\subsection{Carbon Tax}

It is assumed that $\beta=0.3, \alpha=0.7$ in Figure $4 a$, which shows that, without a carbon tax policy, the production of new and remanufactured products is not affected by the carbon tax policy. Also, the production of new products is always greater than that of remanufactured products. However, with a carbon tax policy, the production of new and remanufactured products declines with a rise in carbon tax, in line with Corollary 3(1). Additionally, when $t>0.55$, the production of remanufactured products is negative due to the fact that higher carbon tax results in the loss of price advantage of remanufactured products. Consumers do not want remanufactured products. This suggests that carbon tax must be within a fixed range, namely, $t<0.55$, to boost the demand for remanufactured products. This sheds light on the design of rational carbon tax by the government to increase the demand for remanufactured products. Figure $4 \mathrm{~b}$ shows that the price of new products is always greater than that of remanufactured products. With a carbon tax policy, the prices of new and remanufactured products go up when carbon tax goes up, in line with Corollary 3(1).

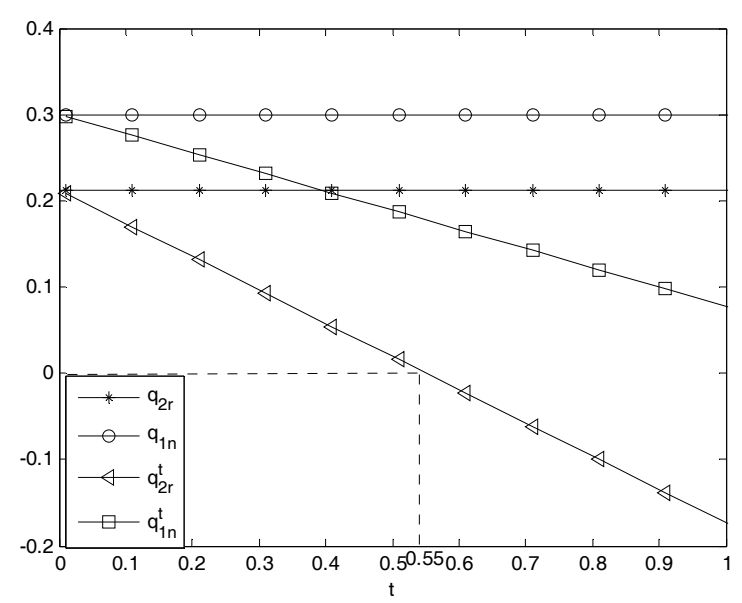

(a) Production of new and remanufactured products changes with carbon tax, with and without carbon tax policy.

Figure 4. Cont. 


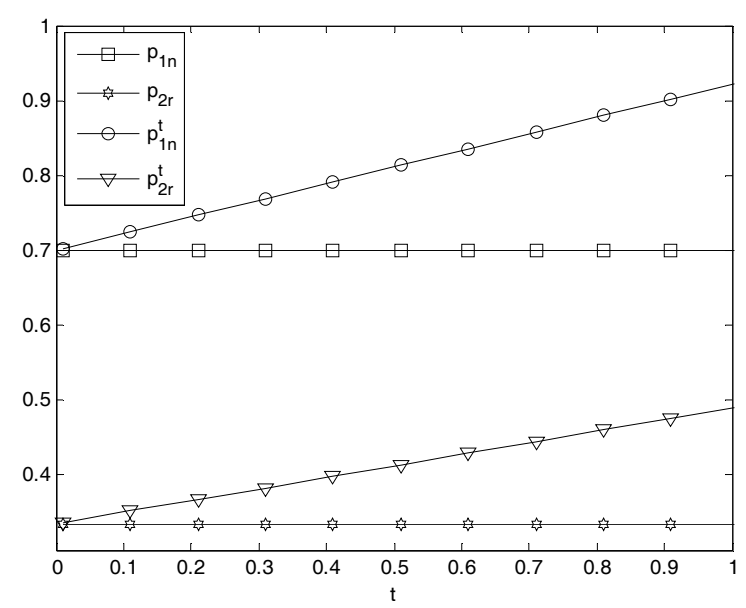

(b) Prices of new and remanufactured products change with carbon tax, with and without a carbon tax policy.

Figure 4. Impacts of changing carbon tax on production and the prices of new and remanufactured products.

Figure 5 assumes that $\beta=0.3, \alpha=0.7, s=0.02, s_{1}=0.04$, in which $\pi$ denotes corporate profits without carbon tax; $\pi^{t}$ denotes corporate profits with carbon tax; $\pi^{t s}$ denotes corporate profits with a carbon tax policy and government subsidies. In Figure 5, comparing corporate profits with and without a carbon tax policy, it is clear that corporate profits tend to dwindle with carbon tax, and thus, the manufacturer loses profits, in line with Corollary 3(1). With government subsidies, corporate profits are stepped up. When $t<0.55$, corporate profits with government subsidies are greater than those without subsidies. When $t>0.55$, the demand for remanufactured products is negative if there are no government subsidies but a carbon tax policy is in place. The number of consumers buying new products tends to increase. Therefore, corporate profits are greater than those with government subsidies and a carbon tax policy. Additionally, when the government subsidy increases $\left(s_{1}=0.04\right)$, corporate profits tend to rise. There is a point of intersection between $\pi^{t s 1}$ and $\pi$, which shows that government subsidies enable corporate profits with carbon tax to rise to the same level as those without a carbon tax policy. This suggests that proper government subsidies and a carbon tax policy do not result in enterprises losing their profits, thereby providing a new insight for governments and enterprises. That is to say, government subsidies can offset the loss of corporate profits, which can safeguard the interest of enterprises and conserve the environment.

Figure 6 assumes that $\beta=0.2, \alpha=0.8, s=0.01, s_{1}=0.2$. $C^{t s}$ denotes the total from carbon emissions with a carbon tax policy and government subsidies in place. Figure 6 shows that the total carbon emissions, as well as the profits of enterprises, decline when carbon tax goes up, in line with Corollary 4(1). With government subsidies, corporate profits increase with a rise in government subsidies, while the total carbon emissions from enterprises also increase with a rise in government subsidies. This contradicts the primary purpose of providing government subsidies, namely, reducing carbon emissions from enterprises. Interestingly, Figure 6 shows that increased government subsidies have a more positive impact on corporate profits than the negative effects brought by a rise in carbon emissions. When $t_{1}<t<t_{2}$, a rise in government subsidies $\left(s_{1}=0.2\right)$ enables the corporate profits to be greater than those when carbon tax is 0 . Meanwhile, carbon emissions from enterprises are lower than when carbon tax is 0 , in line with the TON programs described in Miao et al. (2016) [6]. This interesting finding indicates that the government is motivated to provide subsidies to enterprises even though there is no external incentive or pressure. This promotes corporate developments, curbs carbon emissions, and brings environmental benefits. Also, this shows that a rational government subsidy can increase corporate profits and benefit the environment. 


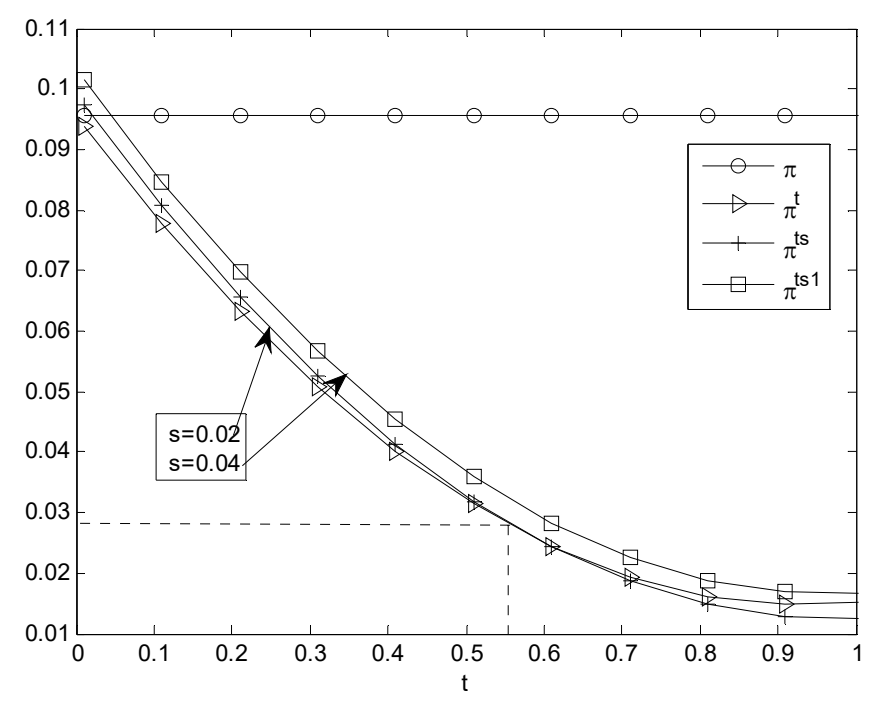

Figure 5. Profits of enterprises change with carbon tax.

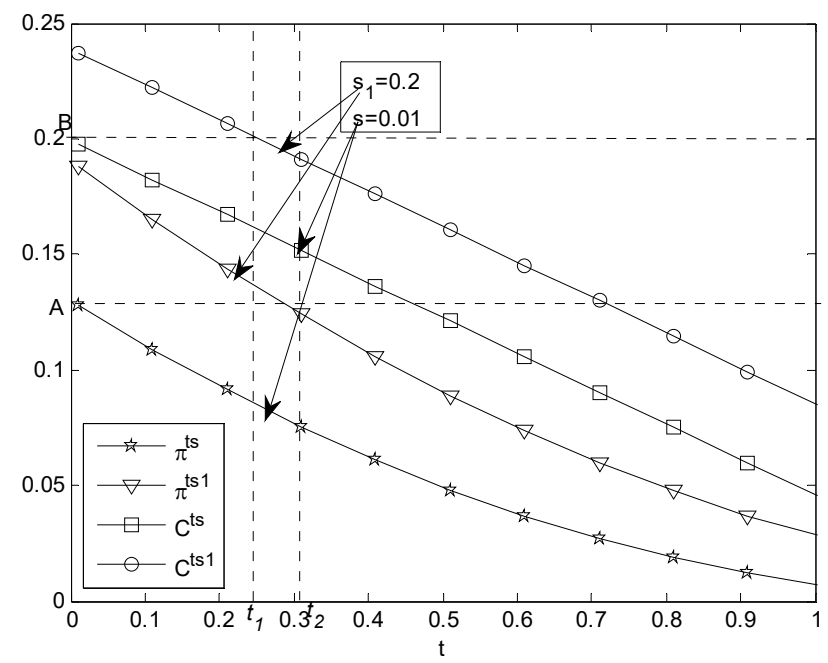

Figure 6. Profits and carbon emissions of enterprises change with carbon tax.

\subsection{Government Subsidies}

In Figure 7, it is assumed that $\beta=0.3, \alpha=0.7, t=0.3$. Figure 7a shows that, compared with the case without government subsidies, government subsidies boost the production of remanufactured products tremendously. When $s_{1}=0.04$, the production of remanufactured products is greater than that when $s=0.02$, which suggests that the production of remanufactured products increases with a rise in government subsidies, while the production of remanufactured products is constantly less than that of new products with a carbon tax policy, in line with Corollary 5. Government subsidies can offset the extra cost of carbon tax, and thus, the quantity of remanufactured products tends to increase with a rise in subsidies. This finding can provide a solution for the government to address the sluggishness caused by carbon tax policies. It can be seen from Figure $7 \mathrm{~b}$ that the price of remanufactured products increases with a rise in government subsidies, in line with Corollary 5. This shows that government subsidies are conducive to enterprise profit. Figure $7 \mathrm{c}$ shows that when the government subsidy is $s=0.23$, the profits of manufacturers in TOR programs with government subsidies and a carbon tax policy are the same as those in TOR programs without a carbon tax policy. From the governmental perspective, the optimal subsidy program is $s=0.23$. This can safeguard the manufacturer's interest and boost the demand for remanufactured products, playing a proactive role in a reduction in carbon emissions. 


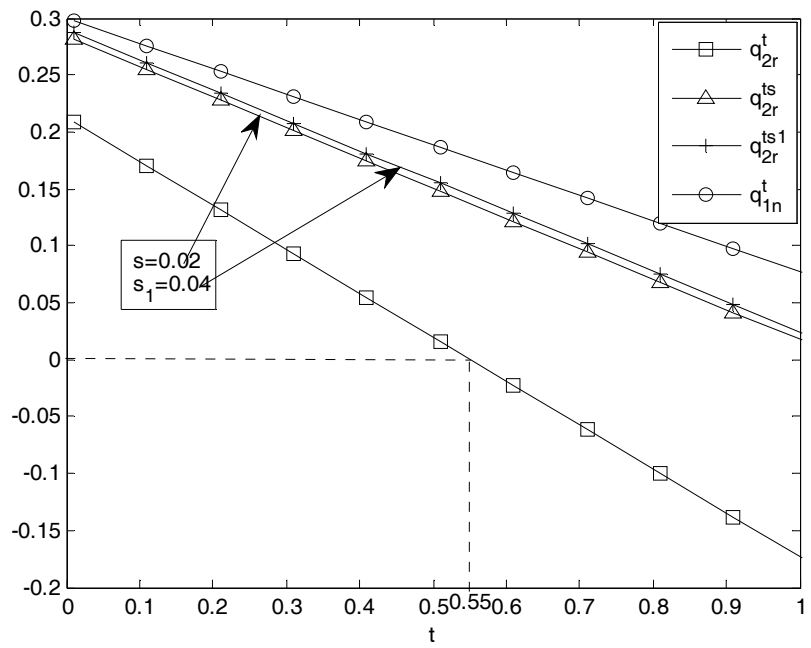

(a) Demand for new and remanufactured products changes with government subsidies and carbon tax.

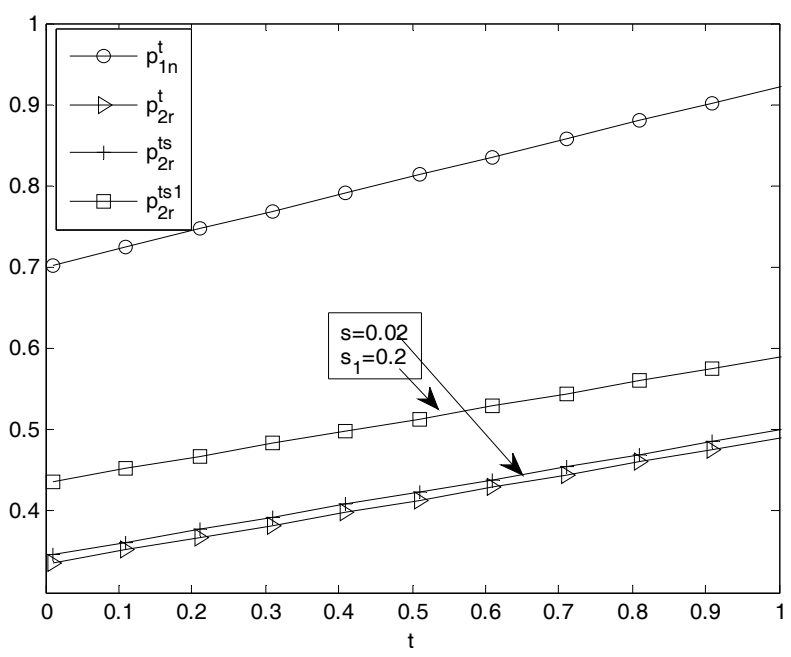

(b) Prices of new and remanufactured products change with government subsidies and carbon tax.

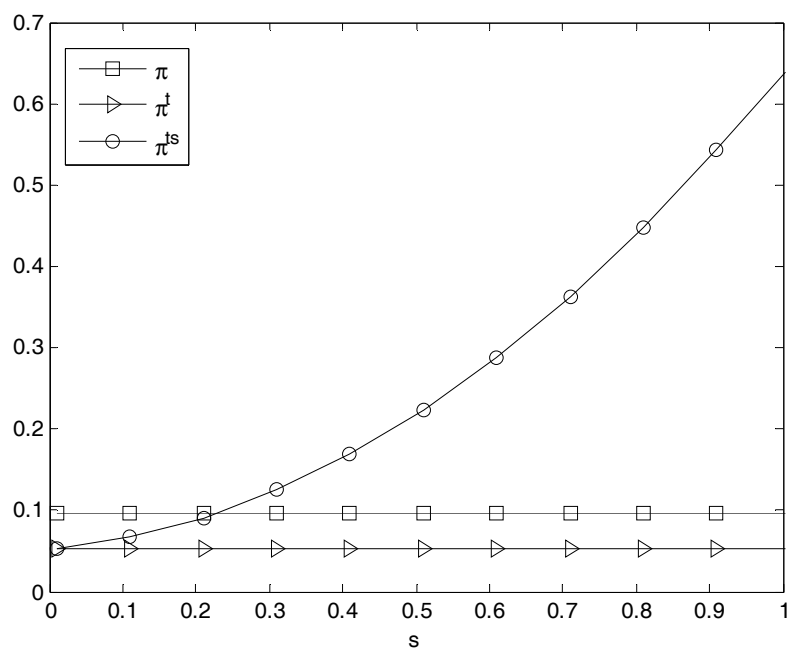

(c) Profits of new and remanufactured products change with government subsidies.

Figure 7. Impacts of changing government subsidies $s$ on production, prices and profits of new products and remanufactured products. 


\section{Conclusions}

Affected by a growing concern for the environment, enterprises and governments are encountering increasing pressure to conserve energy and reduce emissions. Remanufacturing makes it possible to recycle and reuse products and materials. Much research has shown that remanufacturing significantly improves performance in enterprises and the environment. Consumers show bias against remanufactured products, leading to a sluggish market for remanufactured products. As a result, our article describes some methods to encourage consumers to engage in TOR programs. Additionally, introducing a carbon tax policy serves as one of the means of energy conservation and emission reduction. Our article establishes a model of implementing TOR programs with carbon tax and government subsidies, investigating the impacts of TOR programs with carbon tax and government subsidies on the performance of the environment, enterprises, and society. Some findings from the analyses and comparison of models are highlighted. (1) Not all enterprises are suited to TOR programs with a carbon tax policy. When $\beta+c_{r}-p_{u} \leq \alpha, \beta \geq \alpha-\left(c_{r}-p_{u}\right) / c$, enterprises can implement TOR programs with carbon tax. Additionally, when enterprises implement TOR programs with carbon tax and government subsidies, enterprises should determine the optimal pricing and production strategies through matching consumers' willingness to pay, product durability, carbon tax, and government subsidies. (2) In terms of implications for government policies, a rise in consumers' willingness to pay, a fall in the durability of new products, and a rise in TOR discounts, government subsidies, and carbon tax play pivotal roles in encouraging consumers to engage in TOR programs. Of these factors, raising the carbon tax results in the suffering of enterprise profits, while the other methods can increase the profits of enterprises. (3) From the environmental perspective, TOR programs with a carbon tax policy lower the carbon emissions of enterprises. Contrary to intuition, a rebound of carbon emissions from enterprises may result from a rise in consumers' willingness to pay for remanufactured products, a drop in the durability of new products, and a rise in government subsidies. (4) Overall, carbon tax may lead to a decline in the sales of new and remanufactured products, and then enterprises lose profits. Interestingly, the proper carbon tax $\left(t_{1}<t<t_{2}\right)$ and government subsidies can offset the negative effects. Within this range, enterprises can enhance their profitability and curb carbon emissions. This offsets the loss of corporate profits as a result of a carbon tax policy. Furthermore, we have shown by numerical examples that when government subsidies $s=0.23$, manufacturers' profits are the same as those when no carbon tax is introduced. In other words, manufacturers' profits do not suffer. Therefore, from the perspective of government, the subsidy $s=0.23$ is the best.

From a brand new perspective, our article investigates the impacts of a carbon tax policy and government subsidies on TOR programs, and there are some interesting findings. However, some research questions are unanswered, and thus, the future research directions are as follows. (1) It was assumed that the production of new products and the production of remanufactured products are independent of each other, while they are interconnected in reality. Hence, the assumption may be relaxed in future research. (2) Practically, the quality of each recycled product differs, and the discrepancy between product quality should be considered in the future. (3) Our article only centers on carbon tax, and future research may examine the issues of carbon footprints, carbon trade, and carbon quota. Also, increasing public awareness and improving remanufacturing technology could be taken into account. (4) In real life, nonlocal manufacturers may compete with local ones, and thus, it is essential to explore TOR programs with a carbon tax policy in a competitive environment. (5) Currently, the research on the advantages and disadvantages of TOR programs involves models and theories, and remanufacturing has already matured with recent developments. Consequently, it is vital to study TOR programs with a carbon tax policy empirically. (6) Our paper does not consider the identity of the recycling subject, but in future research, we may consider whether a retailer/manufacturer/third party is the leader of recycling, so as to maximize the overall profit of a TOR closed-loop supply chain under a carbon tax policy. (7) When there are two retailers, do they compete or cooperate during the implementation of TOR, and which strategy maximizes the overall profit of the supply chain? 
Author Contributions: In this article, T.S. proposed the main idea and revised it many times; C.H. constructed the model, analyzed the data and made the calculation; and S.C., S.W. and K.K.L. have made insightful comments on different versions of this paper.

Acknowledgments: This paper is financially supported by the National Natural Science Foundation of China (71771080, 71172194, 71521061, 71790593, 71642006, 71473155, 71390335 and 71571065).

Conflicts of Interest: The authors declare no conflicts of interest.

\section{Appendix A}

Proof. Proof of Proposition 1: When $p_{1 n}$ and $p_{2 r}$, the profit $\prod^{n t *}$ is the concave function in a strict sense. The optimal conditions of Lagrangian and Karush-Kuhn-Tucker in Model (1) are as follows.

$$
\begin{gathered}
\Pi\left(p_{1 n}, p_{2 r}\right)=\phi\left(1-p_{1 n}\right)\left(p_{1 n}-c\right)+\delta \phi\left(1-\frac{p_{2 r}-p_{u}}{\alpha-\beta}\right)\left(p_{2 r}-c_{r}\right)+\lambda_{1}\left(\frac{p_{2 r}-p_{u}}{\alpha-\beta}-1\right)+\lambda_{2}\left(\frac{p_{2 r}-p_{u}}{\alpha-\beta}-p_{1 n}\right) \\
\frac{\partial L}{\partial p_{1 n}}=\phi\left(c-p_{1 n}\right)-\phi\left(p_{1 n}-1\right) \\
\frac{\partial L}{\partial 22 r}=\frac{\delta \phi(c r-p 2 r)}{\alpha-\beta}-\frac{\delta \phi(c r-p 2 r)}{(\alpha-\beta)-1} \\
\lambda_{1}\left(\left(p_{2 r}-p_{u}\right) /(\alpha-\beta)-1\right)=0 \\
\lambda_{2}\left(\left(p_{2 r}-p_{u}\right) /(\alpha-\beta)-p_{1 n}\right)=0
\end{gathered}
$$

There are four cases, depending on whether the multiplier is zero or positive. However, $\lambda_{1}>0$ and $\lambda_{2}>0$ correspond to the second stage in which no consumers purchase remanufactured products or use waste products, and hence, this contradicts the assumption that consumers participate in TOR events. Therefore, three cases are further explored, and below are the results.

Case N1. $\left(\lambda_{1}=0\right.$ and $\left.\lambda_{2}=0\right)$

In light of Equations (A1) and (A2), the result is

$$
P_{1 n}^{*}=\frac{1+c}{2} \text { and } p_{2 r}^{*}=\frac{\alpha-\beta+c_{r}+p_{u}}{2}
$$

Substituting it into the market demand function in Model (1), the result is

$$
q_{1 n}^{*}=\frac{1-c}{2} \text { and } q_{2 r}^{*}=\frac{\alpha-\beta-c_{r}+p_{u}}{2(\alpha-\beta)}
$$

As the constraints in Model (1) must not be negative, $p_{1 n}^{*}$ and $p_{2 r}^{*}$ are substituted into the constraints in Model (1), and the requirement for solving this scheme is $\beta+c_{r}-p_{u} \leq \alpha, \beta \geq$ $\alpha-\left(c_{r}-p_{u}\right) / c$.

Case N2. $\left(\lambda_{1} \succ 0\right.$ and $\left.\lambda_{2}=0\right)$

When $\lambda_{1} \succ 0$, the result is

$$
\left(p_{2 r}-p_{u}\right) /(\alpha-\beta)-1=0 .
$$

In light of Equations (A1), (A2) and (A5), the result is

$$
P_{1 n}^{*}=\frac{1+c}{2}, p_{2 r}^{*}=\alpha-\beta+p_{u} \text { and } \lambda_{1}=-\frac{\delta \phi\left(\alpha-\beta-c_{r}+p_{u}\right)}{\alpha-\beta}
$$

Substituting it into the market demand function in Model (1), the result is

$$
q_{1 n}^{*}=\frac{1-c}{2}, q_{2 r}^{*}=0
$$

The value of $\lambda_{1}$ must be positive, while the second constraint in Model (1) must not be negative. The requirement of solving this scheme is $\alpha \leq \beta+c_{r}-p_{u}, \beta \geq \alpha-\left(c_{r}-p_{u}\right) / c$.

Case N3. $\left(\lambda_{1} \succ 0\right.$ and $\left.\lambda_{2}=0\right)$ 
When $\lambda_{2} \succ 0$,

$$
\left(p_{2 r}-p_{u}\right) /(\alpha-\beta)-p_{1 n}=0
$$

can be derived.

In light of Equations (A1), (A2) and (A6), the results are

$$
p_{1 n}^{*}=\frac{1+c+\delta\left(\alpha-\beta+c_{r}-p_{u}\right)}{2+2 \delta(\alpha-\beta)}, p_{2 r}^{*}=\frac{(\alpha-\beta)\left(1+c+\delta\left(\alpha-\beta+c_{r}+p_{u}\right)\right)+2 p_{u}}{2+2 \delta(\alpha-\beta)}, \lambda_{2}=-\frac{\delta \phi\left(c_{r}-p_{u}-c(\alpha-\beta)\right)}{(\alpha-\beta)(\delta(\alpha-\beta)+1)}
$$

Substituting it into the market demand function in Model (1), the result is

$$
q_{1 n}^{*}=\frac{1-c+\delta\left(\alpha-\beta-c_{r}+p_{u}\right)}{2 \delta(\alpha-\beta)+2}, q_{2 r}^{*}=\frac{1-c+\delta\left(\alpha-\beta-c_{r}+p_{u}\right)}{2 \delta(\alpha-\beta)+2}
$$

The value of $\lambda_{1}$ must be positive, while the first constraint in Model (1) must not be negative. The requirement of solving this equation is $\beta \leq \alpha-\left(c_{r}-p_{u}\right) / c, \alpha \geq \beta+c_{r}-p_{u}$. Substituting each optimal solution into the target function, the optimal profits of each scheme can be obtained.

In a similar vein, the proof processes of Propositions 2 and 3 can be obtained.

Proof. Proof of Corollary 2: According to the manufacturer's optimal pricing and production strategies for remanufactured products, because $\left(0<\beta<\alpha<1, p_{u}<c_{r}<c\right)$, the following is achieved by solving the partial derivative.
(a) $\frac{\partial p_{2 r}}{\partial \alpha}=\frac{1}{2}>0, \frac{\partial q_{2 r}}{\partial \alpha}=\frac{c_{r}-p_{u}}{2(\alpha-\beta)^{2}}>0, \frac{\partial \pi}{\partial \alpha}=\frac{\delta \phi\left((\alpha-\beta)^{2}-\left(c_{r}-p_{u}\right)^{2}\right)}{4(\alpha-\beta)^{2}}>0$
(b) $\frac{\partial p_{2 r}}{\partial p_{u}}=\frac{1}{2}>0, \frac{\partial q_{2 r}}{\partial p_{u}}=\frac{1}{2(\alpha-\beta)}>0, \frac{\partial \pi}{\partial p_{u}}=-\frac{\delta \phi\left(\alpha-\beta-c_{r}+p_{u}\right)}{2(\alpha-\beta)}>0$
(c) $\frac{\partial p_{2 r}}{\partial \beta}=-\frac{1}{2}<0, \frac{\partial q_{2 r}}{\partial \beta}=-\frac{c_{r}-p_{u}}{2(\alpha-\beta)^{2}}<0, \frac{\partial \pi}{\partial \beta}=-\frac{\delta \phi\left((\alpha-\beta)^{2}-\left(c_{r}-p_{u}\right)^{2}\right)}{4(\alpha-\beta)^{2}}<0$

Proof. Proof of Corollary 3: Table 3 shows the pricing and production strategies of the optimal new and remanufactured products with a carbon tax policy, and the following is achieved by solving the partial derivative.

$$
\begin{aligned}
& \text { (a) } \frac{\partial p_{1 n}^{t}}{\partial t}=\frac{e_{n}}{2 \phi}>0, \frac{\partial p_{2 r}^{t}}{\partial t}=\frac{e_{r}}{2 \phi \delta}>0, \frac{\partial q_{1 n}^{t}}{\partial t}=-\frac{e_{n}}{2 \phi}<0, \frac{\partial q_{2 r}^{t}}{\partial t}=-\frac{e_{r}}{2 \phi \delta(\alpha-\beta)}<0 \\
& \text { (b) when } \delta e_{n}>e_{r}, \frac{\partial p_{1 n}^{t}}{\partial t}-\frac{\partial p_{2 r}^{t}}{\partial t}=\frac{\left(\delta e_{n}-e_{r}\right)}{2 \phi \delta}>0
\end{aligned}
$$

Proof. Proof of Corollary 4: Where $C_{1 n}^{t}$ denotes the carbon emissions of the new products of enterprises with carbon tax, and $C_{2 r}^{t}$ denotes the carbon emissions of manufactured products of enterprises with carbon tax, and when $C_{1 n}^{t}=q_{1 n}^{t} e_{n}, C_{2 r}^{t}=q_{2 r}^{t} e_{r}$,

$$
\begin{aligned}
& \text { (a) } \frac{\partial C_{1 n}^{t}}{\partial t}=-\frac{e_{n}^{2}}{2 \phi}<0, \frac{\partial C_{2 r}^{t}}{\partial t}=-\frac{e_{r}^{2}}{2 \phi \delta(\alpha-\beta)}<0 \\
& \text { (b) } \frac{\partial q_{2 r}^{*}}{\partial \alpha}=\frac{e_{r} t+\delta \phi\left(c_{r}-p_{u}\right)}{2 \delta \phi(\alpha-\beta)^{2}}>0, \frac{\partial q_{2 r}^{2}}{\partial \beta}=-\frac{e_{r} t+\delta \phi\left(c_{r}-p_{u}\right)}{2 \delta \phi(\alpha-\beta)^{2}}<0
\end{aligned}
$$

Proof. Proof of Corollary 5: Where $C_{2 r}^{t s}$ denotes the amount of carbon emissions from remanufactured products with government subsidies and carbon tax, and $C_{2 r}^{t s}=q_{2 r}^{t s} e_{r}$, according to the manufacturer's 
optimal price and production strategies with carbon tax and government subsidies, the following is achieved.

$$
\frac{\partial p_{2 r}^{t s}}{\partial s}=\frac{1}{2}>0, \frac{\partial q_{2 r}^{t s}}{\partial s}=\frac{1}{2(\alpha-\beta)}>0, \frac{\partial C_{2 r}^{t s}}{\partial s}=\frac{e_{r}}{2(\alpha-\beta)}>0
$$

\section{References}

1. Yang, L.; Ji, J.; Wang, M.; Wang, Z. The manufacturer's joint decisions of channel selections and carbon emission reductions under the cap-and-trade regulation. J. Clean. Prod. 2018, 193, 506-523. [CrossRef]

2. Hovelaque, V.; Bironneau, L. The carbon-constrained EOQ model with carbon emission dependent demand. Int. J. Prod. Econ. 2015, 164, 285-291. [CrossRef]

3. Purohit, A.K.; Shankar, R.; Dey, P.K.; Choudhary, A. Non-stationary stochastic inventory lot-sizing with emission and service level constraints in a carbon cap-and-trade system. J. Clean. Prod. 2016, 113, 654-661. [CrossRef]

4. Ma, X.; Ji, P.; Ho, W.; Yang, C.H. Optimal procurement decision with a carbon tax for the manufacturing industry. Comput. Oper. Res. 2016, 89, 360-368. [CrossRef]

5. Murray, B.; Rivers, N. British Columbia's revenue-neutral carbon tax: A review of the latest "grand experiment" in environmental policy. Energy Policy 2015, 86, 674-683. [CrossRef]

6. Miao, Z.; Mao, H.; Fu, K.; Wang, Y. Remanufacturing with trade-ins under carbon regulations. Comput. Oper. Res. 2016, 89, 253-268. [CrossRef]

7. Han, X.; Yang, Q.; Shang, J.; Pu, X. Optimal strategies for trade-old-for-remanufactured programs: Receptivity, durability, and subsidy. Int. J. Prod. Econ. 2017, 193, 602-616. [CrossRef]

8. Ma, Z.J.; Zhou, Q.; Dai, Y.; Sheu, J.B. Optimal pricing decisions under the coexistence of "trade old for new" and "trade old for remanufactured" programs. Transp. Res. Part E Logist. Transp. Rev. 2017, 106, 337-352. [CrossRef]

9. Mukherjee, K.; Mondal, S. Analysis of issues relating to remanufacturing technology-A case of an Indian company. Technol. Anal. Strateg. Manag. 2009, 21, 639-652. [CrossRef]

10. Shu, T.; Peng, Z.Z.; Chen, S.; Wang, S.Y.; Lai, K.K.; Yang, H. Government subsidy for remanufacturing or carbon tax rebate: Which is better for firms and a low-carbon economy. Sustainability 2017, 9, 156. [CrossRef]

11. Liu, B.; Holmbom, M.; Segerstedt, A.; Chen, W. Effects of carbon emission regulations on remanufacturing decisions with limited information of demand distribution. Int. J. Prod. Res. 2015, 53, 532-548. [CrossRef]

12. Wittneben, B.B.F. Exxon is right: Let us re-examine our choice for a cap-and-trade system over a carbon tax. Energy Policy 2009, 37, 2462-2464. [CrossRef]

13. $\mathrm{Xu}, \mathrm{X}$; He, P. Joint production and pricing decisions for multiple products with cap-and-trade and carbon tax regulations. J. Clean. Prod. 2016, 112, 4093-4106. [CrossRef]

14. Lu, C.; Tong, Q.; Liu, X. The impacts of carbon tax and complementary policies on Chinese economy. Energy Policy 2010, 38, 7278-7285. [CrossRef]

15. Agrawal, V.V.; Ferguson, M.; Souza, G.C. Trade-in rebates for price discrimination and product recovery. IEEE Trans. Eng. Manag. 2016, 63, 326-339. [CrossRef]

16. Zhu, X.; Wang, M.; Chen, G.; Chen, X. The effect of implementing trade-in strategy on duopoly competition. Eur. J. Oper. Res. 2016, 248, 856-868. [CrossRef]

17. Yan, B.; Hong-Yuan, L.I.; Wang, T.; Liu, Y.P. Autonomous trade-in strategy for retailer with market segmentation. J. Manag. Sci. China 2017, 20, 120-136.

18. Xiao, Y. Choosing the right exchange-old-for-new programs for durable goods with a rollover. Eur. J. Oper. Res. 2016, 259, 512-526. [CrossRef]

19. Miao, Z.W.; Fu, K.; Xia, Z.Q.; Wang, Y. Models for closed-loop supply chain with trade-ins. Omega 2017, 66, 308-326. [CrossRef]

20. Liu, J.; Chen, L.; Zhai, X.; University, P. Optimal product rollover strategy under trade-in program. Chin. J. Manag. 2018, 15, 908-917.

21. Liu, J.; Zhai, X.; Chen, L. Optimal pricing strategy under trade-in program in the presence of strategic consumers. Omega 2018. [CrossRef] 
22. Cao, K.; Xu, X.; Bian, Y.; Sun, Y. Optimal trade-in strategy of business-to-consumer platform with dual-format retailing model. Omega 2018. [CrossRef]

23. Huang, Y. A closed-loop supply chain with trade-in strategy under retail competition. Math. Prob. Eng. 2018. [CrossRef]

24. Zhu, X.; Wang, M. Optimal pricing strategy of a hybrid trade old for new and remanufactured products supply chain. Optim. Lett. 2018. [CrossRef]

25. Yang, H.; Luo, J.; Wang, H.; Yang, H.; Luo, J.; Wang, H. The role of revenue sharing and first-mover advantage in emission abatement with carbon tax and consumer environmental awareness. Int. J. Prod. Econ. 2017, 193, 691-702. [CrossRef]

26. Ji, J.; Zhang, Z.; Yang, L. Carbon emission reduction decisions in the retail-/dual-channel supply chain with consumers' preference. J. Clean. Prod. 2017, 141, 852-867. [CrossRef]

27. Wang, C.; Wang, W.; Huang, R. Supply chain enterprise operations and government carbon tax decisions considering carbon emissions. J. Clean. Prod. 2017, 152, 271-280. [CrossRef]

28. Yuan, B.; Gu, B.; Guo, J.; Xia, L.; Xu, C. The optimal decisions for a sustainable supply chain with carbon information asymmetry under cap-and-trade. Sustainability 2018, 10, 1002. [CrossRef]

29. Wang, S.; Wan, L.; Li, T.; Luo, B.; Wang, C. Exploring the effect of cap-and-trade mechanism on firm's production planning and emission reduction strategy. J. Clean. Prod. 2018, 172, 591-601. [CrossRef]

30. Wang, X.; Xue, M.; Xing, L. Analysis of carbon emission reduction in a dual-channel supply chain with cap-and-trade regulation and low-carbon preference. Sustainability 2018, 10, 580. [CrossRef]

31. Cheng, Y.; Xiong, Z.; Luo, Q. Joint pricing and product carbon footprint decisions and coordination of supply chain with cap-and-trade regulation. Sustainability 2018, 10, 481. [CrossRef]

32. Liu, M.W.; Wan, M.Y.; Hong, F.U. Low-carbon technology selection for supply chain under cap and trade mechanism with low-carbon preference. Chin. J. Manag. Sci. 2018, 26, 152-162.

33. Yenipazarli, A. Managing new and remanufactured products to mitigate environmental damage under emissions regulation. Eur. J. Oper. Res. 2016, 249, 117-130. [CrossRef]

34. Yang, A.F.; Wang, J.Q.; Xiao-Jian, H.U. Study on the third-party remanufacturing problem under carbon tax mechanism. Soft Sci. 2017, 31, 134-139.

35. Saxena, L.K.; Jain, P.K.; Sharma, A.K. Tactical supply chain planning for tyre remanufacturing considering carbon tax policy. Int. J. Adv. Manuf. Technol. 2018, 97, 1505-1528. [CrossRef]

36. He, X.; Zhang, J. Supplier Selection Study under the Respective of Low-Carbon Supply Chain: A Hybrid Evaluation Model Based on FA-DEA-AHP. Sustainability 2018, 10, 564. [CrossRef]

37. Zhang, H.; Li, Y.; Han, Y. Research on pricing decisions of manufacturers' recycling and remanufacturing based on carbon tax and low carbon preference. J. Ind. Technol. Econ. 2018, 1, 130-136.

38. Zhou, J.; Deng, Q.; Li, T. Optimal acquisition and remanufacturing policies considering the effect of quality uncertainty on carbon emissions. J. Clean. Prod. 2018, 186, 180-190. [CrossRef]

39. Wang, X.; Zhu, Y.; Sun, H.; Jia, F. Production decisions of new and remanufactured products: Implications for low carbon emission economy. J. Clean. Prod. 2018, 171, 1225-1243. [CrossRef]

40. Turki, S.; Sauvey, C.; Rezg, N. Modelling and optimization of a manufacturing/remanufacturing system with storage facility under carbon cap and trade policy. J. Clean. Prod. 2018, 193, 441-458. [CrossRef]

41. Hu, D.B.; Xiao, C.X.; Chen, X.H. Carbon quotas, subsidies and engineering machinery remanufacturing. Front. Eng. Manag. 2016, 3, 50-58. [CrossRef]

42. Hazen, B.T.; Mollenkopf, D.A.; Wang, Y. Remanufacturing for the circular economy: An examination of consumer switching behavior. Bus. Strategy Environ. 2017, 26, 451-464. [CrossRef]

43. Zhang, H.M.; Liu, B.H.; En-Zhong, L.I.; Zhang, D.; Zhou, X.Y. Effects of carbon trading and subsidy policy on remanufacturing closed-loop supply chain. China Surf. Eng. 2018, 31, 165-174.

44. Souza, G.C. Closed-loop supply chains: A critical review, and future research. Decis. Sci. 2013, 44, 7-38. [CrossRef]

45. Agrawal, V.V.; Thomas, V.M. Is leasing greener than selling? Manag. Sci. 2012, 58, 523-533. [CrossRef]

(C) 2018 by the authors. Licensee MDPI, Basel, Switzerland. This article is an open access article distributed under the terms and conditions of the Creative Commons Attribution (CC BY) license (http://creativecommons.org/licenses/by/4.0/). 